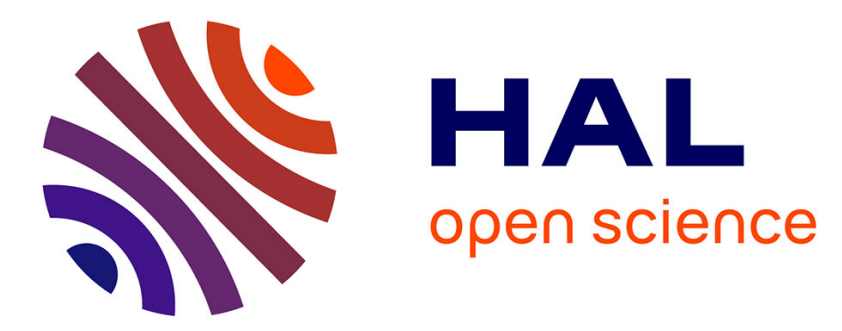

\title{
Part-circular surface cracks in round bars under tension, bending and twisting
}

\author{
Anh Le Van, Jean Royer
}

\section{To cite this version:}

Anh Le Van, Jean Royer. Part-circular surface cracks in round bars under tension, bending and twisting. International Journal of Fracture, 1993, 61 (1), pp.71 - 99. 10.1007/BF00032340 . hal01007176

\section{HAL Id: hal-01007176 \\ https://hal.science/hal-01007176}

Submitted on 18 Nov 2016

HAL is a multi-disciplinary open access archive for the deposit and dissemination of scientific research documents, whether they are published or not. The documents may come from teaching and research institutions in France or abroad, or from public or private research centers.
L'archive ouverte pluridisciplinaire HAL, est destinée au dépôt et à la diffusion de documents scientifiques de niveau recherche, publiés ou non, émanant des établissements d'enseignement et de recherche français ou étrangers, des laboratoires publics ou privés. 


\title{
Part-circular surface cracks in round bars under tension, bending and twisting
}

\author{
A. LEVAN and J. ROYER
}

Laboratoire de Mécanique des Structures, Ecole Centrale de Nantes, 1 rue de la Noë, Nantes 44072 Cedex 03, France

\begin{abstract}
Circular-fronted cracks in round bars subject to tension, bending and twisting are considered. Numerical expressions are given allowing the calculation of stress intensity factors $K_{\mathrm{I}}, K_{\mathrm{II}}, K_{\mathrm{III}}$ at every point on the crack front for a wide range of crack geometries. Comparisons are made with analytical, experimental and numerical results available in the literature. Crack shapes satisfying the iso- $K_{1}$ criterion are also determined, making it possible to investigate the problem of crack growth behaviour under tensile or bending fatigue loads.
\end{abstract}

\section{Introduction}

As cylindrical specimens are easily machined, components with a round cross section are commonly used in engineering structures. Bars, shafts, wires, reinforcements, bolts, screws or pins are examples of cylindrically-shaped structural elements. In many applications the loading conditions are quite complex. Under cyclic or repeated loads, fatigue cracks can occur in such components. Experimental works [1-5] showed that surface cracks created by fatigue have approximately circular fronts. In order to predict the growth of such a crack and the strength of the cracked component, an accurate stress analysis is required. Under linear elastic conditions, this leads us to precisely calculate the stress intensity factors which govern the mechanical state in the structure. In the general case of a combined load, a mixed mode I + II + III situation exists along the crack front. As in any arbitrary three-dimensional configuration, the variation of stress intensity factors $K_{\mathrm{I}}, K_{\mathrm{II}}, K_{\mathrm{III}}$ on the crack front must be taken into account.

Several works have been devoted to the problem of a surface crack in a round bar. Table 1 summarizes the main features of some studies relating to this problem. In Table $1, K_{\mathrm{IA}}$ denotes the stress intensity factor at the deepest point of the crack, $K_{\mathrm{IB}}$ the stress intensity factor at the surface terminal point (intersection between the lateral surface and the crack front), $\bar{K}_{I}$ the average stress intensity factor calculated on the crack front. Additionally, straight-fronted cracks are considered as particular cases of circular or semi-elliptical cracks. The bibliography, although representative, makes no claim to completeness - rather, it is a selection of the many references found in this field.

In this paper, use is made of a boundary integral equation specifically developed for fracture problems [22] to determine the stress intensity factors $K_{\mathrm{I}}, K_{\mathrm{II}}, K_{\mathrm{III}}$ for circular-fronted cracks in a round bar subjected to tension, bending and torsion. Polynomial expressions are provided allowing the calculation of these stress intensity factors at every point on the crack front for a wide range of crack geometries. Crack shapes satisfying the iso- $K_{I}$ criterion are computed, and the problem of crack growth behaviour under tensile or bending fatigue loads is discussed. The results are compared with other experimental and numerical results available in the literature 


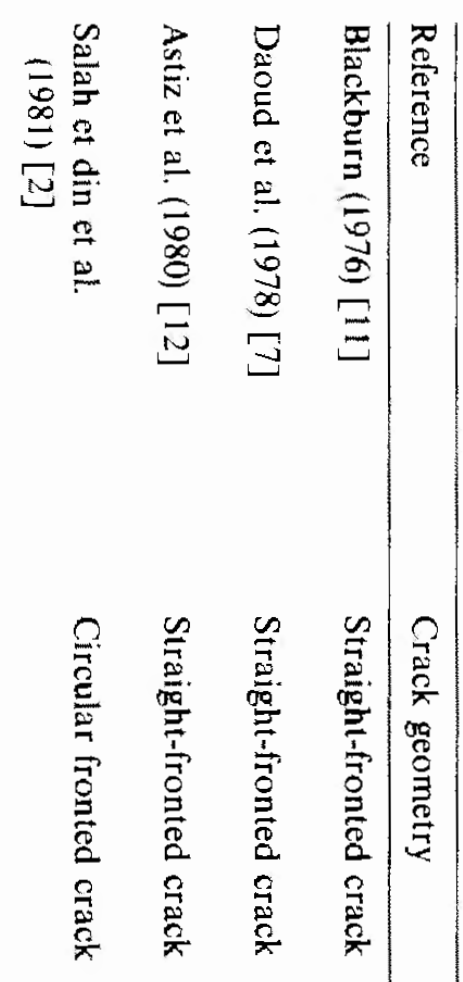

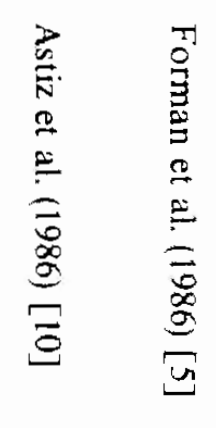

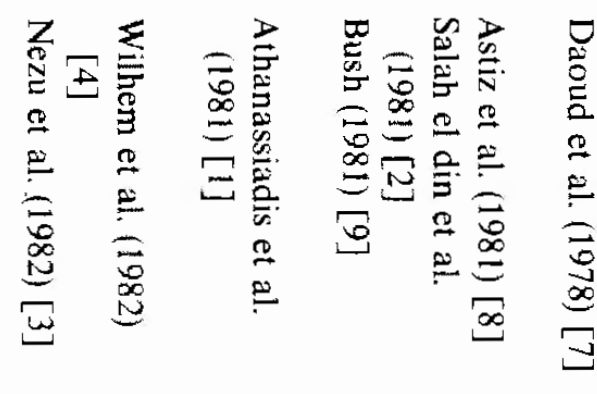

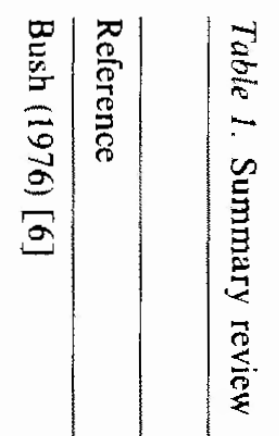

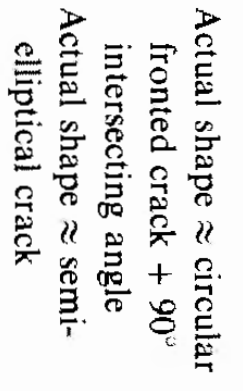

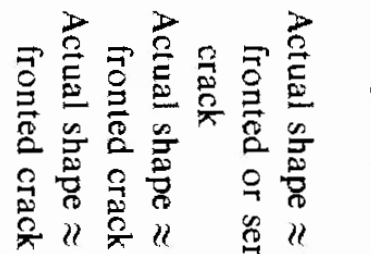

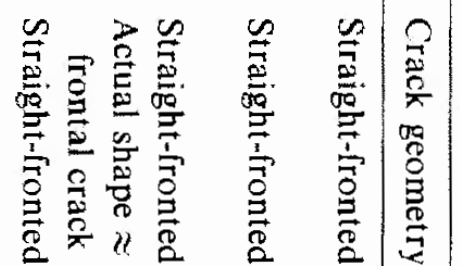

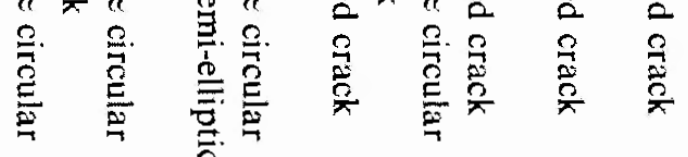

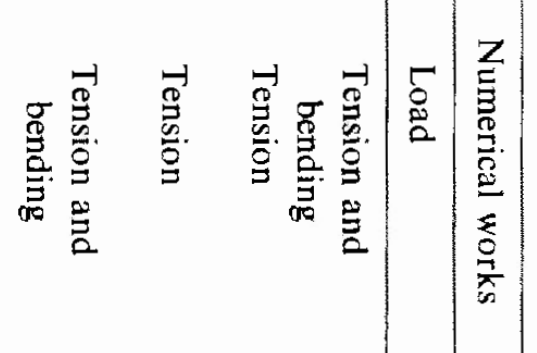

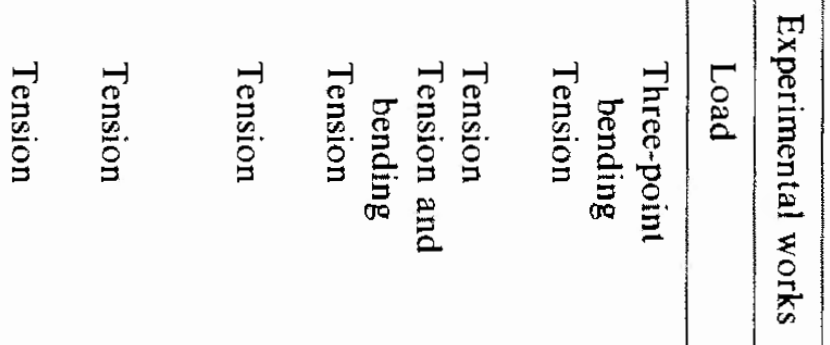

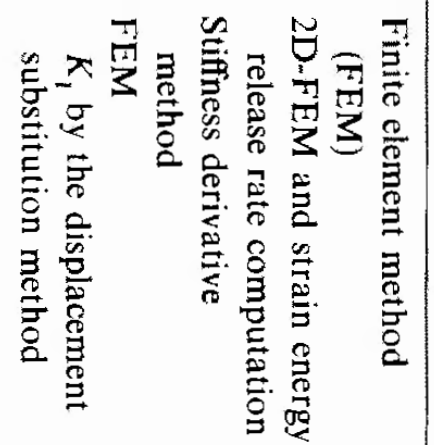

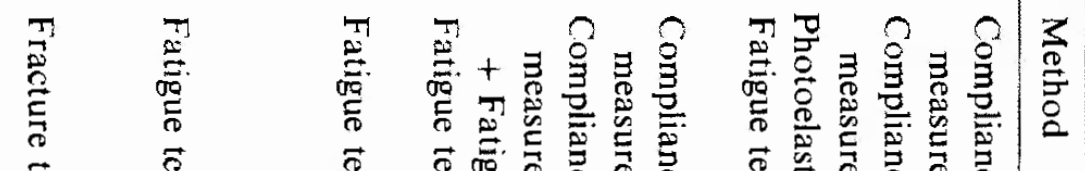

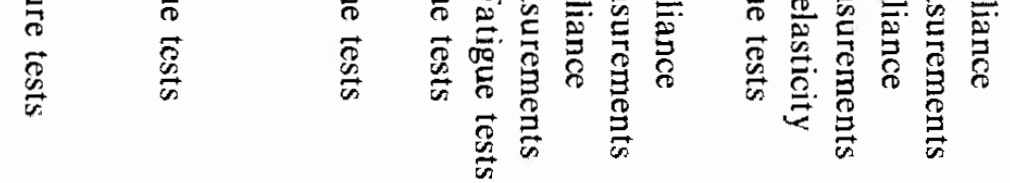
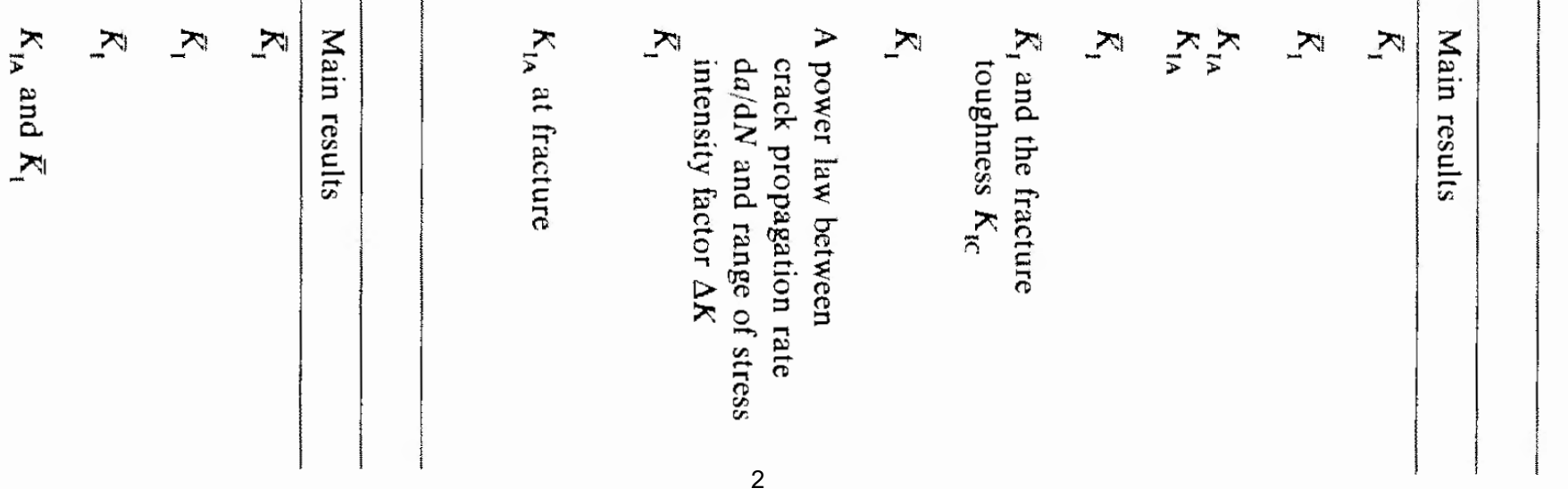


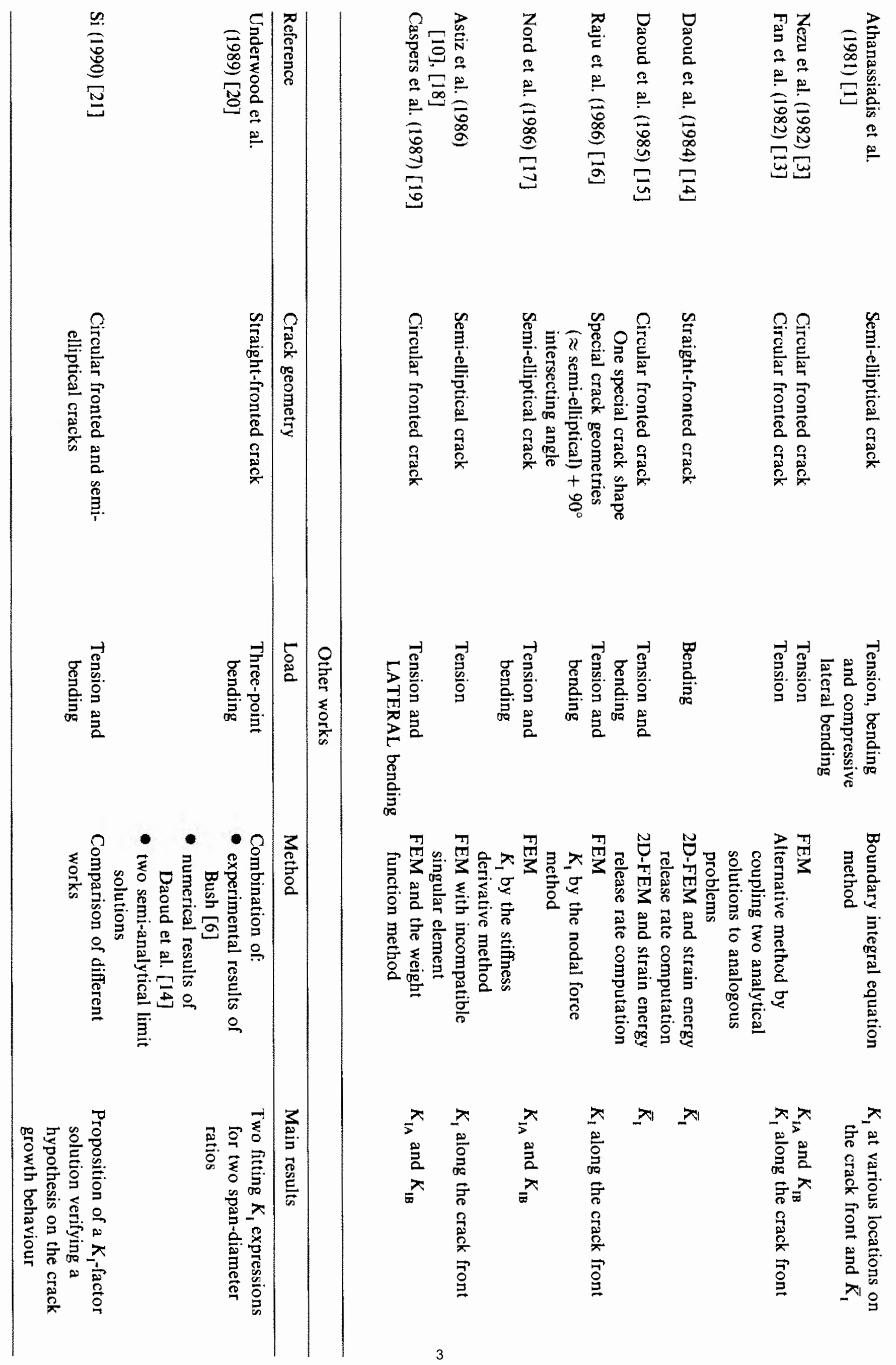


for mode I crack problems. Comparisons are also made with analytical results for some limit configurations.

\section{Formulation}

\subsection{Geometry}

Figure 1 represents a round bar of radius $R$ and height $h \gg R$ containing in its median cross section a surface crack. The crack front is part of a circle of radius $R^{\prime}$. When $R^{\prime}$ equals the crack depth $a$, the crack is a so-called semi-circular crack. On the other hand, when $R^{\prime}$ tends to infinity, the crack is referred to as 'straight-fronted'. Any intermediate crack geometry between the two above limiting cases can be defined by the crack shape parameter $\alpha \equiv B_{0} B / B_{0} B_{1}$, $\alpha \in[0,1]$ (Fig. 2). The computation is carried out on 4 crack shapes: $\alpha=0$ (semi-circular), $\frac{1}{3}, \frac{2}{3}$ and 1 (straight-fronted). The two intermediate cracks have been determined in such a way that they divide arc $B_{0} N_{1}$ into three equal sub-arcs. Six relative crack depths are considered: $a / R=0.04,0.12,0.24,0.40,0.60,0.85$. Since there are 4 crack shapes for each crack depth, 24 crack geometries are analyzed (Fig. 3).
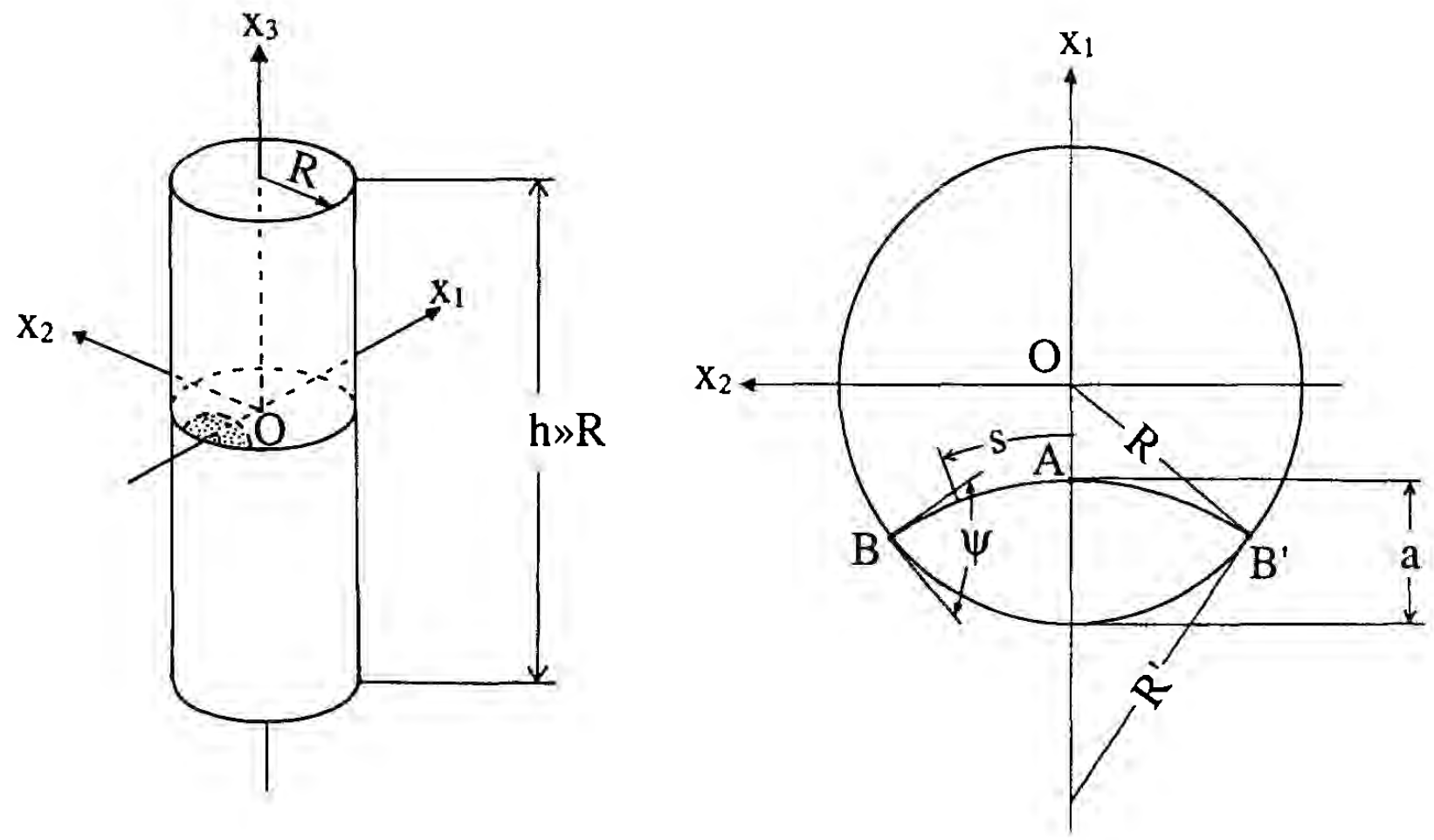

Fig. 1. Geometry.

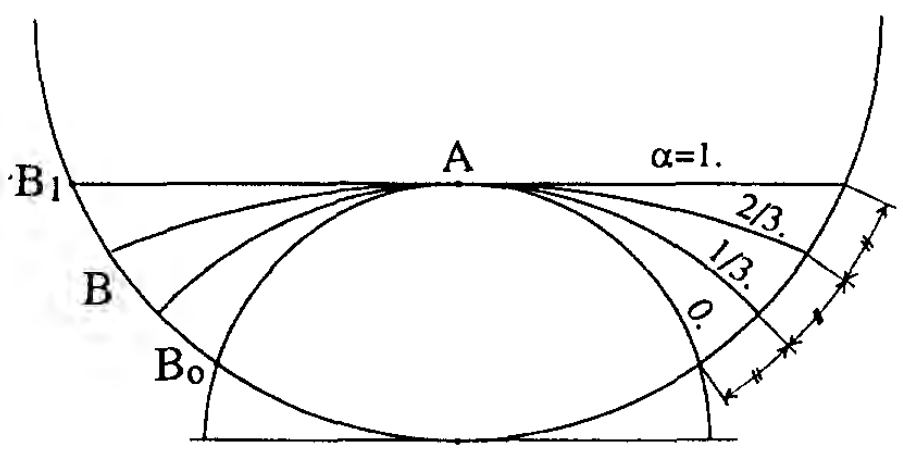

Fig. 2. Crack shapes defined by parameter $x$.

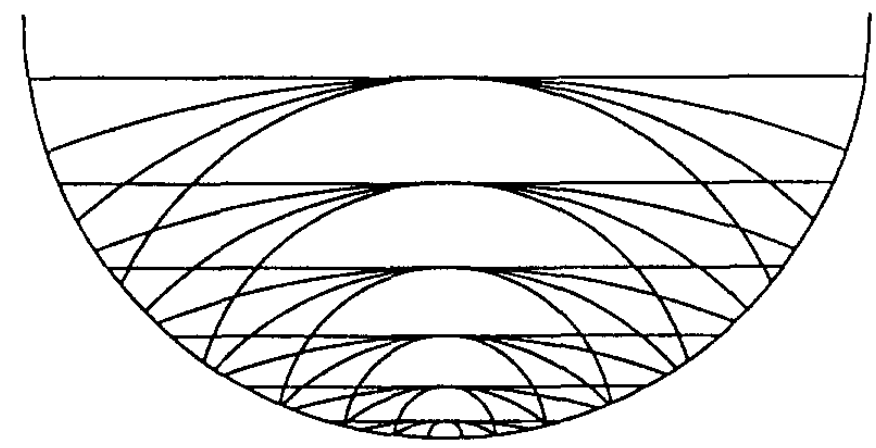

Fig. 3. Computed crack geometries. 


\subsection{Loads}

The bar is successively subjected at its ends to three loads (Fig. 4):

- a uniform tensile stress $\sigma$.

- a linear tensile stress with outer fiber maximal value $\sigma_{m}$.

- a linearly distributed shear with outer fiber maximal value $\tau_{m}$, resulting from torques twisting the bar.

As far as stress intensity factor solutions are concerned, these loads are respectively equivalent to a uniform pressure, a linear pressure and an axisymmetrical linear shear applied on the crack faces.

\subsection{Equations of the problem}

The bar is assumed to be made up of a homogeneous, isotropic, linear elastic material characterized by Young's modulus $E$ and Poisson's ratio $v$. For solving the problem use is made of the integral equation given in [22]. Let us introduce the following notations:

- $x$ : field point with co-ordinates $\left(x_{1}, x_{2}, x_{3}\right)$ in a rectilinear rectangular system of axes $\mathrm{Oe}_{1} \mathbf{e}_{2} \mathbf{e}_{3}$ (Fig. 1)

- $x_{0}$ : $\quad$ source point, $r=\left\|x-x_{0}\right\|, \mathbf{e}_{\mathrm{r}}=\left(x-x_{0}\right) / r$ (Fig. 5)

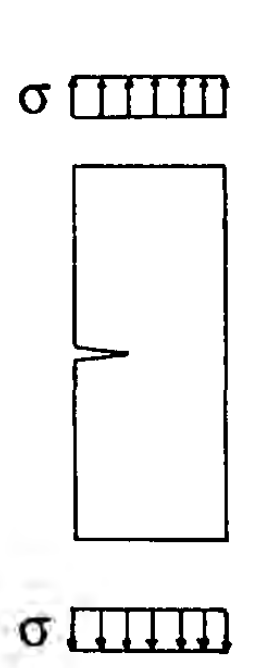

a

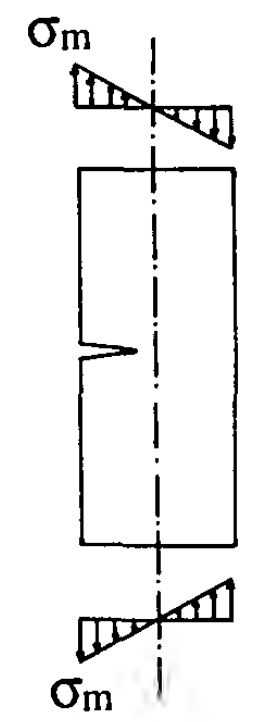

b

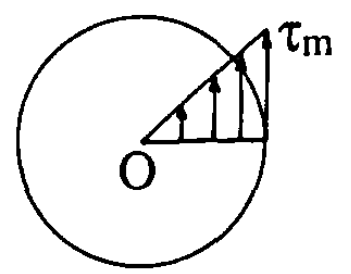

c

Fig. 4. Loads. (a) Tension. (b) Bending. (c) Torison.
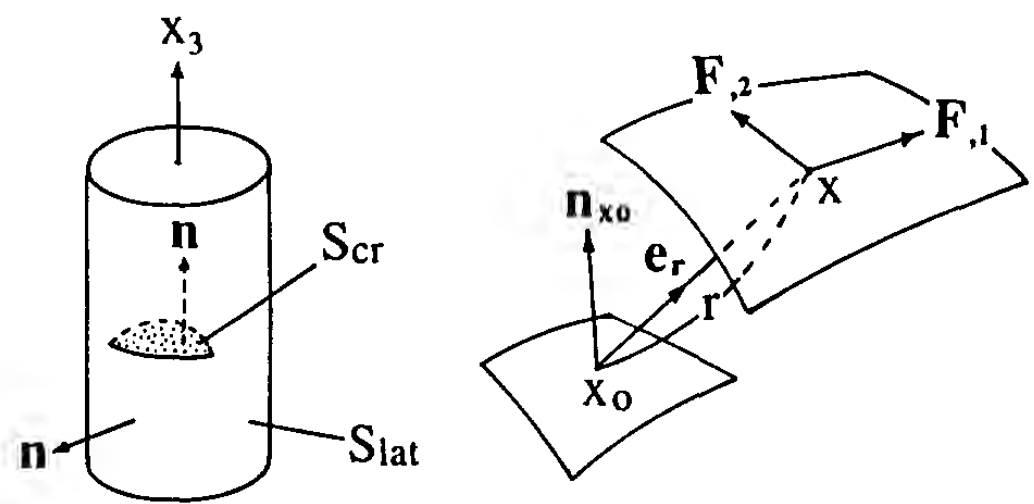

Fig. 5. Variables of the integral equation set. 
- $\mathbf{t}\left(x_{0}, \mathbf{n}_{x 0}\right)$ : the stress vector at $x_{0}$, related to normal $\mathbf{n}_{x 0}$.

- $S_{\mathrm{cr}}$ : the surface of the crack, which is represented by a Cartesian parametrization

$F_{\mathrm{cr}}: \Delta_{\mathrm{cr}} \ni\left(x_{1}, x_{2}\right) \rightarrow x \in S_{\mathrm{cr}}$

- $S_{\mathrm{lat}}$ : the cylindrical lateral surface of the bar, which admits the parameterization

$$
F_{\text {lat }}: \Delta_{\text {lat }}=\left[0,2 \pi\left[\times[-h, h] \ni\left(\theta, x_{3}\right) \rightarrow x \in S_{\text {lat }} .\right.\right.
$$

In fact, the lateral surface $S_{\text {lat }}$ also includes the upper and lower flat bases of the bar, and another surface must be added at the junction of the bases and the cylindrical surface (Fig. 6) in order to avoid any discontinuity of the normal vector on $S_{\text {lat }}$. The outer surface of the bar is then sufficiently smooth as required by the theory.

- $\varphi_{\mathrm{cr}}: S_{\mathrm{cr}} \ni x \rightarrow \varphi_{\mathrm{cr}}(x) \in \mathbb{R}^{3}, \varphi_{\mathrm{lat}}: S_{\mathrm{lat}} \ni x \rightarrow \varphi_{\mathrm{lat}}(x) \in \mathbb{R}^{3}:$ the unknown densities defined respectively on $S_{\mathrm{cr}}$ and $S_{\mathrm{lat}}$, which are shown to be equal to the displacement jumps through the surfaces $S_{\mathrm{cr}}$ and $S_{\text {lat }}$ respectively [23], [24].

- $\Phi_{\mathrm{cr}}=\varphi_{\mathrm{cr}} \odot F_{\mathrm{cr}}, \Phi_{\mathrm{lat}}=\varphi_{\mathrm{lat}} \approx F_{\text {lat }}$ (compounds of functions $F$ and $\varphi$ ).

The set of equations of the problem can then be written in the following form, which expresses the stress vector at any point $x_{0}$ and related to normal $\mathbf{n}_{x 0}$, in terms of the densities $\varphi_{\mathrm{cr}}$ and $\varphi_{\text {lat }}$ :

$$
\begin{aligned}
& \forall x_{0} \in S_{\mathrm{cr}}, \quad p v \int_{\Delta_{\mathrm{cr}}} \operatorname{Ker}_{\mathrm{cr}}\left(\phi_{\mathrm{cr}}, x_{0}, x\right) \mathrm{d} x_{1} \mathrm{~d} x_{2}+\int_{\Delta_{\mathrm{lat}}} \operatorname{Ker}_{\mathrm{lat}}\left(\phi_{\text {lat }}, x_{0}, x\right) \mathrm{d} \theta \mathrm{d} x_{3}=\mathbf{t}\left(x_{0}, \mathbf{n}_{x 0}\right), \\
& \forall x_{0} \in S_{\mathrm{lat}}, \quad \int_{\Delta_{\mathrm{cr}}} \operatorname{Ker}_{\mathrm{cr}}\left(\phi_{\mathrm{cr}}, x_{0}, x\right) \mathrm{d} x_{1} d x_{2}+p v \int_{\Delta_{\mathrm{lat}}} \operatorname{Ker}_{\mathrm{lat}}\left(\phi_{\mathrm{lat}}, x_{0}, x\right) \mathrm{d} \theta \mathrm{d} x_{3}=\mathbf{t}\left(x_{0}, \mathbf{n}_{x 0}\right),
\end{aligned}
$$
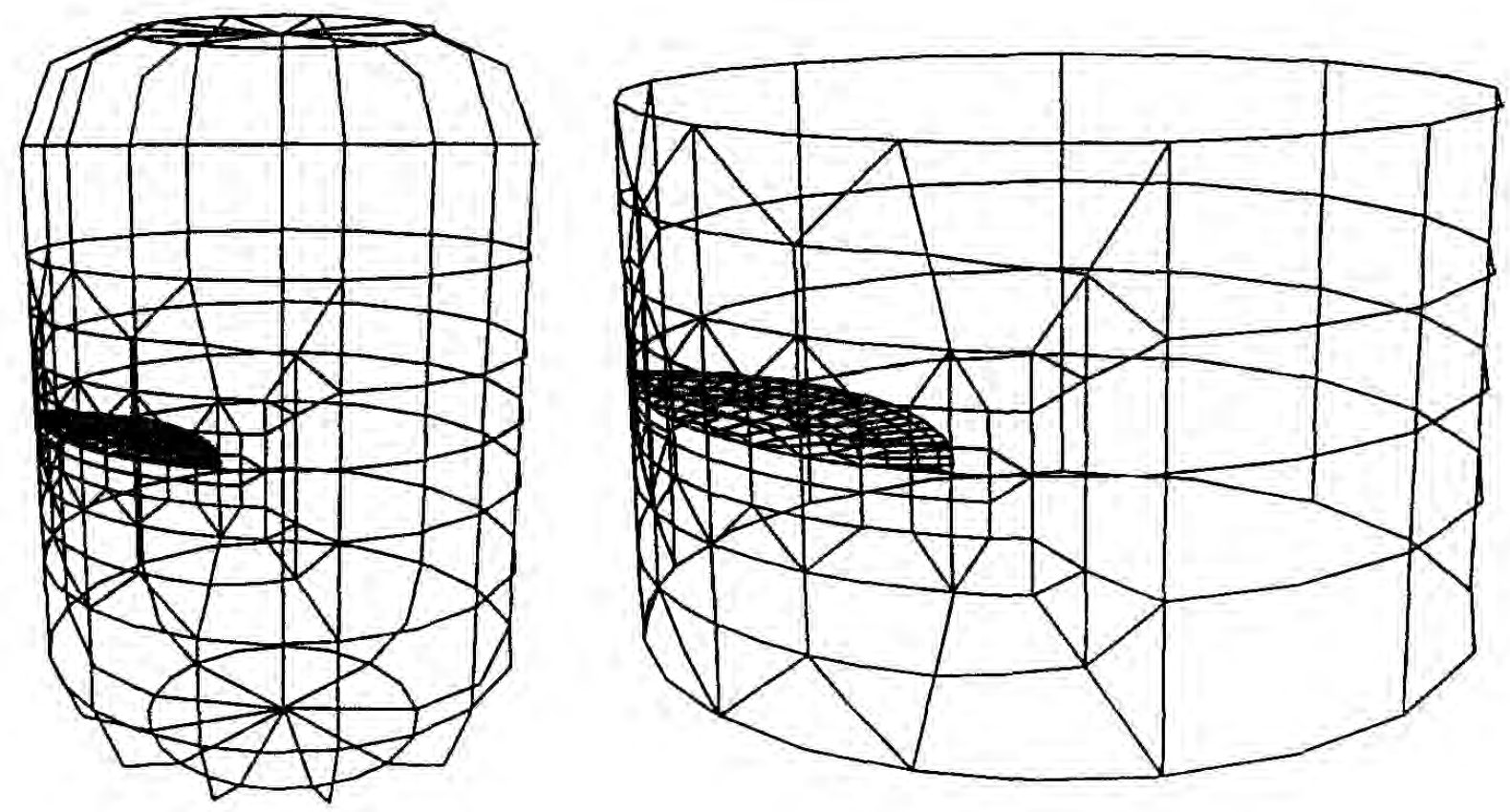

Fig. 6. Typical mesh modelling the cracked bar. 
where $\mathrm{Ker}_{\mathrm{cr}}$ and $\mathrm{Ker}_{\mathrm{lat}}$ are the kernels defined by

$$
\begin{aligned}
\operatorname{Ker}\left(\Phi, x_{0}, x\right)= & \frac{E}{16 \pi\left(1-v^{2}\right)} \frac{\varepsilon_{3 \alpha \beta}}{r^{2}}\left\{2\left(\mathbf{F}_{, \beta}, \Phi_{, \alpha}, \mathbf{e}_{r}\right) \mathbf{n}_{x 0}-(1-2 v)\left[\left(\Phi_{, \alpha}, \mathbf{e}_{r}, \mathbf{n}_{x 0}\right) \mathbf{F}_{, \beta}\right.\right. \\
& \left.\left.+\left(\mathbf{F}_{, \beta} \mathbf{n}_{x 0}\right) \Phi_{, \alpha} \wedge \mathbf{e}_{r}\right]+3\left(\mathbf{e}_{r} \Phi_{, \alpha}\right)\left[\left(\mathbf{F}_{, \beta}, \mathbf{n}_{x 0}, \mathbf{e}_{r}\right) \mathbf{e}_{r}+\left(\mathbf{n}_{x 0} \mathbf{e}_{r}\right) \mathbf{e}_{r} \wedge \mathbf{F}_{, \beta}\right]\right\}
\end{aligned}
$$

In relation (2), $\varepsilon_{i j k}$ is the Levi-Civita symbol. The function $F$ is defined by $F: \Delta \ni\left(u_{1}, u_{2}\right) \rightarrow x, \alpha$, $\beta \in\{1,2\}$

For $\operatorname{Ker}_{\mathrm{cr}}:\left(u_{1}, u_{2}\right)=\left(x_{1}, x_{2}\right), F=F_{\mathrm{cr}}, \Phi=\Phi_{\mathrm{cr}}, \mathbf{n}_{x 0}=\mathbf{e}_{3}$

For $\operatorname{Ker}_{\text {lat }}:\left(u_{1}, u_{2}\right)=\left(\theta, x_{3}\right), F=F_{\text {lat }}, \Phi=\Phi_{\text {lat }}, \mathbf{n}_{x 0}$ is the outward normal at the point $x_{0}$ to the lateral surface.

The symbol $p v$ before $\int$ indicates that the integral is understood in the sense of the principal value.

Partial derivatives of any function $f$ with respect to variables $u_{i}$ is denoted $f_{i,}$. Implicit summation is made over any repeated index.

The stress vector at the point $x_{0}$ is written in (1) as the sum of the surface intergals over the crack and the lateral surface of the bar. Eventually one has to solve the coupled set of equations (1) with unknowns $\varphi_{\mathrm{cr}}$ and $\varphi_{\text {lat }}$.

\section{Numerical results}

For all numerical purposes, the Poisson's ratio $v$ is taken as equal to 0.3. Both the crack and the lateral surface are discretized into finite elements and Eqns. (1) are solved by the collection method. Figure 6 shows a typical mesh modelling the cracked bar. Eight-node or six-node isoparametric 2D elements are used throughout the structure. Quarter-point elements [25] are specifically used along the crack front. Depending on the surface to which the element belongs, the geometry transformation and the interpolation of the density are performed with different variables [26]:

- for elements belonging to the crack surface, the mapped variables through geometric transformation are Cartesian co-ordinates $\left(x_{1}, x_{2}\right) \in \Delta_{\mathrm{cr}}$ and the interpolated functions are Cartesian components of $\varphi_{\mathrm{cr}}, \varphi_{1}, \varphi_{2}$ and $\varphi_{3}$

- for elements belonging to the lateral surface of the bar, the mapped variables are cylindrical coordinates $\left(\theta, x_{3}\right) \in \Delta_{\text {lat }}$ and the interpolated functions are here again Cartesian components of $\varphi_{\text {lat }}$ for simplicity. Cylindrical variables $\left(\theta, x_{3}\right)$ allow us to shape the finite elements into curved elements fitting the cylindrical surface. However, this cannot be seen in Fig. 6 since the sides of the elements are represented by segments.

The mesh covers the crack surface together with the lateral free surface. Of course, if the different loads were treated separately, then symmetries or skew-symmetries could be exploited in order to reduce the problem to the study of one quarter or one half of the bar, provided adequate boundary conditions are added. This approach is not chosen here for two reasons: first, the whole structure is preserved so that several loads can be applied simultaneously, thus requiring 
only one solution of the algebraic system. Secondly, the matrix of the system being fully populated and moreover non-symmetrical (as is the case with any boundary integral equation method), obtaining symmetrical or skew-symmetrical final results ensures the accuracy of input data.

Eventually, the solution of the discretized equation of (1) provides the densities $\varphi_{\mathrm{cr}}$ and $\varphi_{\text {lat }}$, which in turn yield the complete elastic solution for the problem of the cracked bar, in particular the stress intensity factors can be evaluated along the crack front. Figure 7 shows the deformation of the lateral surface under a tensile load and of the crack under torsion. The latter is strongly emphasized in order to make it visible, explaining why some points on the crack seem to overlap the crack surface.

The normalized stress intensity factors at any point located on the crack front are determined as follows, using the notations of Fig. 8:

(a) Case of a uniform pressure on the crack (tensile load):

$$
\frac{K_{\mathrm{I}}}{\sigma \sqrt{\pi a}}=\frac{1}{\sigma \sqrt{\pi a}} \frac{E}{8\left(1-v^{2}\right)} \lim _{p \rightarrow 0}\left\{\varphi_{3} \sqrt{\frac{2 \pi}{\rho}}\right\}=\frac{2 \pi \sqrt{2 \pi}}{\sigma \sqrt{\pi a}} \lim _{\rho \rightarrow 0}\left\{\frac{E}{16 \pi\left(1-v^{2}\right)} \frac{\varphi_{3}}{\sqrt{\rho}}\right\},
$$

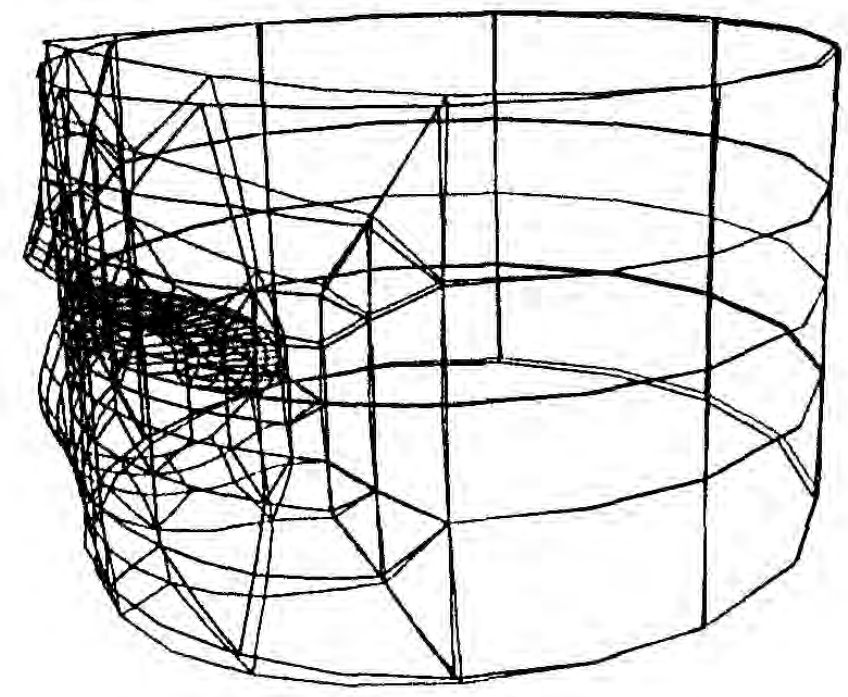

a

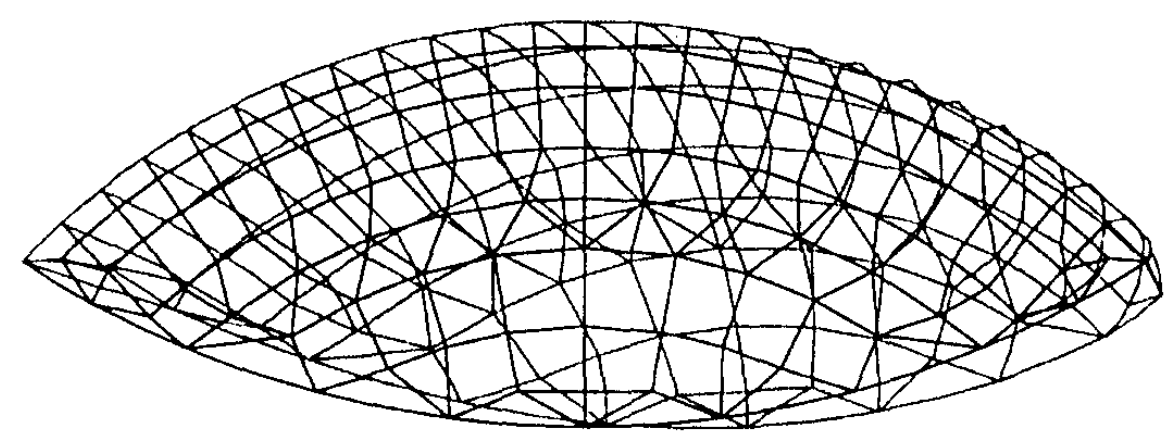

b

Fic. 7. (a) Deformation of the lateral surface under tensile loading. (b) Deformation of the crack under torsion. 


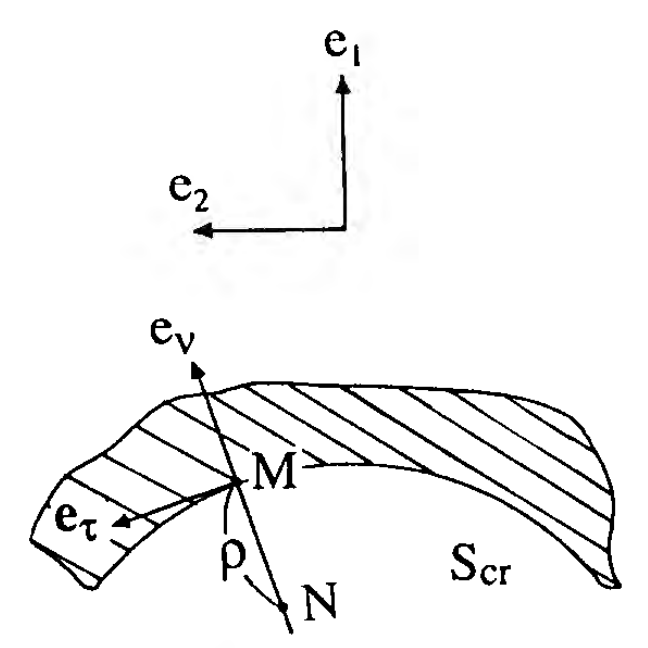

Fig. 8. Determination of stress intensity factors. $\rho=$ Distance to the crack front. $\mathbf{e}_{v}$ : in-plane normal to the crack front, outward with respect to the crack. $\mathbf{e}_{\tau}$ : in-plane tangent, $\mathbf{e}_{\tau}=\mathbf{e}_{3} \wedge \mathbf{e}_{v}$.

(b) case of a linear pressure on the crack (bending load):

$$
\frac{K_{1}}{\sigma_{m} \sqrt{\pi a}}=\frac{1}{\sigma_{m} \sqrt{\pi a}} \frac{E}{8\left(1-v^{2}\right)} \lim _{\rho \rightarrow 0}\left\{\varphi_{3} \sqrt{\frac{2 \pi}{\rho}}\right\}=\frac{2 \pi \sqrt{2 \pi}}{\sigma_{m} \sqrt{\pi a}} \lim _{\rho \rightarrow 0}\left\{\frac{E}{16 \pi\left(1-v^{2}\right)} \frac{\varphi_{3}}{\sqrt{\rho}}\right\},
$$

(c) case of a linear shear on the crack (torsion):

$$
\begin{aligned}
& \frac{K_{\mathrm{II}}}{\tau_{m} \sqrt{\pi a}}=\frac{1}{\tau_{m} \sqrt{\pi a}} \frac{E}{8\left(1-v^{2}\right)} \lim _{\rho \rightarrow 0}\left\{\varphi_{v} \sqrt{\frac{2 \pi}{\rho}}\right\}=\frac{2 \pi \sqrt{2 \pi}}{\tau_{m} \sqrt{\pi a}} \lim _{\rho \rightarrow 0}\left\{\frac{E}{16 \pi\left(1-v^{2}\right)} \frac{\varphi_{v}}{\sqrt{\rho}}\right\}, \\
& \frac{K_{\mathrm{III}}}{\tau_{m} \sqrt{\pi a}}=\frac{1}{\tau_{m} \sqrt{\pi a}} \frac{E}{8(1+\nu)} \lim _{\rho \rightarrow 0}\left\{\varphi_{\tau} \sqrt{\frac{2 \pi}{\rho}}\right\}=\frac{2 \pi \sqrt{2 \pi}}{\tau_{m} \sqrt{\pi a}}(1-v) \lim _{\rho \rightarrow 0}\left\{\frac{E}{16 \pi\left(1-v^{2}\right)} \frac{\varphi_{\tau}}{\sqrt{\rho}}\right\},
\end{aligned}
$$

where $\varphi_{v}, \varphi_{\tau}, \varphi_{3}$ are components of $\varphi_{\text {cr }}$ in the local basis $\left(\mathbf{e}_{v}, \mathbf{e}_{\tau}, \mathbf{e}_{3}\right)$ generally varying along the crack front (Fig. 8).

It should be mentioned that relations (3) are taken just as definitions for series intensity factors without any assumption on the elastic state at the point of interest. Neither plane stress nor plane strain states, which are certainly predominant at the neighbourhood of the free surface or the deepest point of the crack, are assumed. The transition from one state to another will not be discussed in this paper.

As shown by (2), solving (1) gives directly $E /\left(16 \pi\left(1-v^{2}\right)\right) \varphi_{\mathrm{cr}}$ - the term bracketed together in (3) - explaining why it is unnecessary to specify the value of Young's modulus $E$ when computing stress intensity factors. Figure 9 shows the stress intensity factors obtained for the geometry corresponding to $a / R=0.4$ and $\alpha=1$, versus the relative abcissa $s / s_{m}$ (Following the notations in Fig. 1, $s$ is the curvilinear abcissa of a point on the crack front, $s_{m}$ is arc length $A B$, $s / s_{m}=-1$ at $B^{\prime},=+1$ at $B$ ).

Thus, for each geometry, 4 discrete curves are obtained corresponding respectively to $K_{\mathrm{I}}$ in tension, $K_{\mathrm{I}}$ in bending, $K_{\mathrm{II}}$ and $K_{\mathrm{III}}$ in twisting. As predicted, the $K_{\mathrm{I}}$ value in the bending case is always smaller than that in tensile loading at homologous points on the crack front. As for $K_{\mathrm{III}}$ values, they are found to be negative for all geometries. The negative sign of $K_{\mathrm{III}}$ is merely due to the fact that $\varphi_{3}$ equals the normal displacement at the upper crack face minus that at the lower face, and to the choice of the local basis orientation as shown in Fig. 8. 


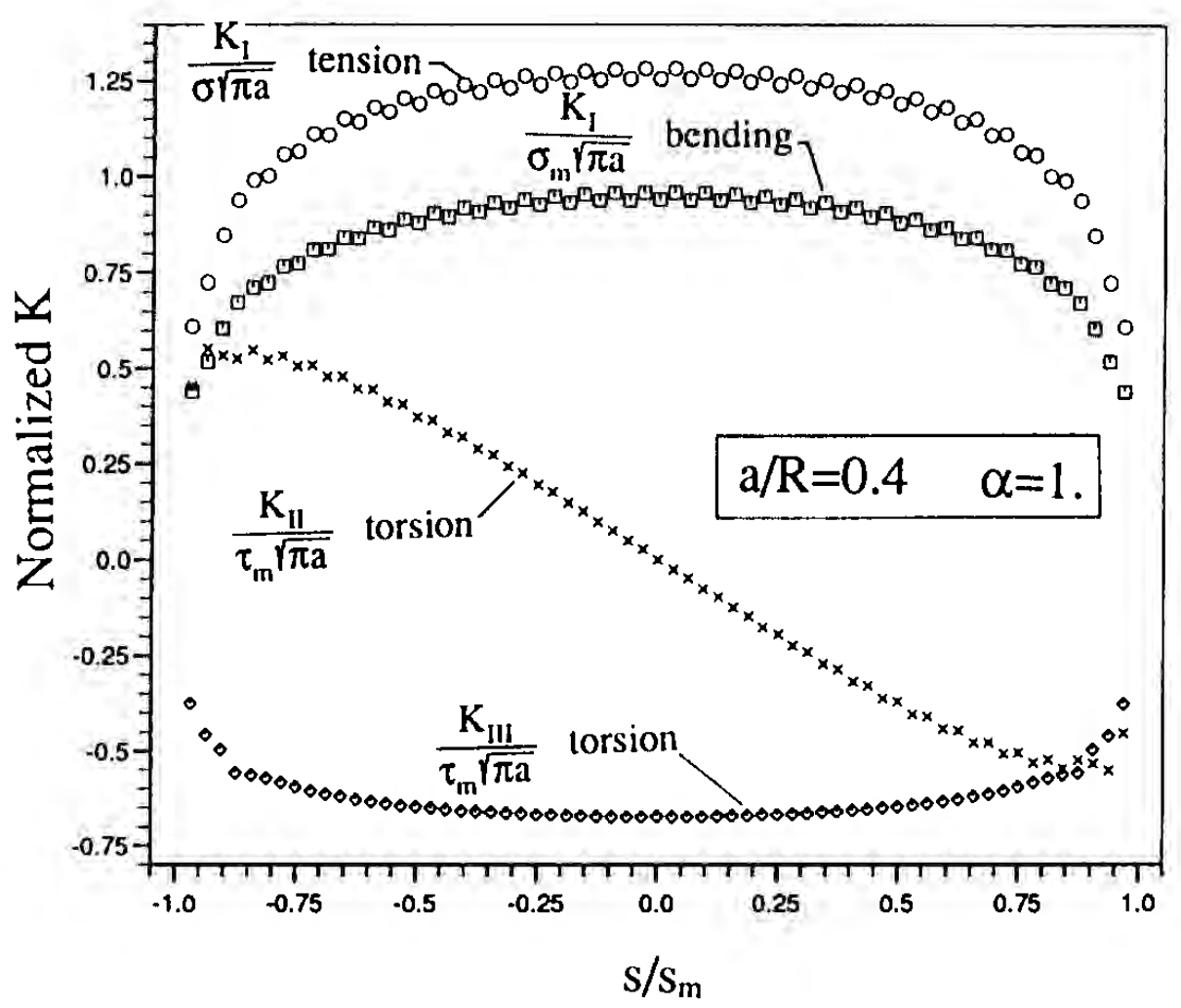

Fig. 9. Normalized stress intensity factors along the crack front. $s=$ curvilinear abcissa, $s_{m}=\operatorname{arc~length~} \mathrm{AB}$ (see Fig. 1).

Now using the least square method, the set of discrete values of stress intensity factors obtained for the 24 computed geometries are fitted in the following polynomial form:

(a) in the tension case: $\frac{K_{1}}{\sigma \sqrt{\pi a}}=\sum_{i=0}^{3} \sum_{j=0}^{3} \sum_{k=0.2,4,6} C_{i j k}^{(\mathrm{lt})}\left(\frac{a}{R}\right)^{i} \alpha^{j}\left(\frac{s}{s_{m}}\right)^{k}$,

(b) in the bending case: $\frac{K_{1}}{\sigma_{m} \sqrt{\pi a}}=\sum_{i=0}^{3} \sum_{j=0}^{3} \sum_{k=0,2,4,6} C_{i j k}^{(\mathrm{lb})}\left(\frac{a}{R}\right)^{i} \alpha^{j}\left(\frac{s}{s_{m}}\right)^{k}$,

(c) in the tension case: $\frac{K_{\mathrm{II}}}{\tau_{m} \sqrt{\pi a}}=\sum_{i=0}^{3} \sum_{j=0}^{3} \sum_{k=1,3} C_{i j k}^{(\mathrm{II})}\left(\frac{a}{R}\right)^{i} \alpha^{j}\left(\frac{s}{s_{m}}\right)^{k}$

$$
\frac{K_{\text {III }}}{\tau_{m} \sqrt{\pi a}}=\sum_{i=0}^{3} \sum_{j=0}^{3} \sum_{k=0,2,4,6} C_{i j k}^{(\text {(III) }}\left(\frac{a}{R}\right)^{i} \alpha^{j}\left(\frac{s}{s_{m}}\right)^{k},
$$

where the $C_{i j k}$ coefficients are given in Table 2 . All mean quadratic errors resulting from the fitting expressions (4) are about 1 percent, which is quite acceptable when compared to the accuracy of the finite element method. Expressions (4) should be used with crack depths of less than one-half diameter $(0 \leqslant a / R \leqslant 0.9)$ and with $\alpha \in[0,1]$. Figure 10 depicts the variation of normalized stress intensity factors $K_{\mathrm{I}}$ in tension and $K_{\mathrm{II}}$ in torsion as a function of the crack shape $\alpha$ and the relative abcissa $s / s_{m}$ when the relative crack depth is 0.4 . It is clearly shown that for nearly straight-fronted cracks $(\alpha \approx 1) K_{1}$ is maximum at the deepest point of the crack $\left(s / s_{m}=0\right)$, and for semi-circular cracks $(\alpha \approx 0)$ the maximum value for $K_{1}$ is reached in the neighbourhood of the free surface $\left(\left|s / s_{m}\right| \approx 1\right)$. As for $K_{\mathrm{II}}$, it varies almost linearly with either $\alpha$ or $s / s_{m}$. 
Table 2. $C_{i j k}$ coefficients

\begin{tabular}{|c|c|c|c|c|c|c|c|c|c|}
\hline$i$ & $j$ & $k$ & $\begin{array}{l}C_{i j k}^{(\mathrm{IT})} \\
\text { for tension }\end{array}$ & $\begin{array}{l}C_{i j k}^{(\mathrm{Ib})} \\
\text { for bending }\end{array}$ & $\begin{array}{l}C_{i j k}^{(\mathrm{III})} \\
\text { for torsion }\end{array}$ & $i$ & $j$ & $k$ & $\begin{array}{l}C_{i j k}^{(1)} \\
\text { for torsion }\end{array}$ \\
\hline 0 & 0 & 0 & $0.66837 \mathrm{E}+00$ & $0.67003 \mathrm{E}+00$ & $-0.48863 \mathrm{E}+00$ & 0 & 0 & 1 & $-0.12653 \mathrm{E}+01$ \\
\hline 0 & 0 & 2 & $-0.12819 E+00$ & $-0.11851 E+00$ & $0.53272 \mathrm{E}+00$ & 0 & 0 & 3 & $0.54361 E+00$ \\
\hline 0 & 0 & 4 & $0.65362 E+00$ & $0.62139 E+00$ & $-0.66724 \mathrm{E}-01$ & 0 & 1 & 1 & $0.28415 \mathrm{E}+01$ \\
\hline 0 & 0 & 6 & $-0.63476 \mathrm{E}+00$ & $-0.60142 E+00$ & $-0.12661 \mathrm{E}+00$ & 0 & 1 & 3 & $-0.89110 \mathrm{E}+00$ \\
\hline 0 & 1 & 0 & $0.14917 \mathrm{E}+01$ & $0.14660 \mathrm{E}+01$ & $-0.12523 E+01$ & 0 & 2 & 1 & $-0.29326 \mathrm{E}+01$ \\
\hline 0 & 1 & 2 & $-0.15181 \mathrm{E}+01$ & $-0.14844 \mathrm{E}+01$ & $-0.60349 E+00$ & 0 & 2 & 3 & $0.10159 \mathrm{E}+01$ \\
\hline 0 & 1 & 4 & $0.17418 \mathrm{E}+01$ & $0.17943 \mathrm{E}+01$ & $-0.49469 E+01$ & 0 & 3 & 1 & $0.11584 \mathrm{E}+01$ \\
\hline 0 & 1 & 6 & $-0.36700 \mathrm{E}+01$ & $-0.36828 E+01$ & $0.70620 \mathrm{E}+01$ & 0 & 3 & 3 & $-0.66930 E+00$ \\
\hline 0 & 2 & 0 & $-0.17108 \mathrm{E}+01$ & $-0.16117 \mathrm{E}+01$ & $0.15275 E+01$ & 1 & 0 & 1 & $0.81442 \mathrm{E}+00$ \\
\hline 0 & 2 & 2 & $0.34585 \mathrm{E}+01$ & $0.34011 \mathrm{E}+01$ & $-0.16732 E+00$ & 1 & 0 & 3 & $-0.14275 E+01$ \\
\hline 0 & 2 & 4 & $-0.11730 \mathrm{E}+02$ & $-0.11906 \mathrm{E}+02$ & $0.17182 \mathrm{E}+02$ & 1 & 1 & 1 & $-0.13862 \mathrm{E}+02$ \\
\hline 0 & 2 & 6 & $0.14317 \mathrm{E}+02$ & $0.14447 \mathrm{E}+02$ & $-0.22195 E+02$ & 1 & 1 & 3 & $0.55863 \mathrm{E}+01$ \\
\hline 0 & 3 & 0 & $0.67685 E+00$ & $0.61063 \mathrm{E}+00$ & $-0.66148 E+00$ & 1 & 2 & 1 & $0.12860 \mathrm{E}+02$ \\
\hline 0 & 3 & 2 & $-0.22663 E+01$ & $-0.22579 E+01$ & $0.53588 \mathrm{E}+00$ & 1 & 2 & 3 & $-0.21359 E+01$ \\
\hline 0 & 3 & 4 & $0.85036 \mathrm{E}+01$ & $0.86794 \mathrm{E}+01$ & $-0.11410 \mathrm{E}+02$ & 1 & 3 & 1 & $-0.25711 \mathrm{E}+01$ \\
\hline 0 & 3 & 6 & $-0.93203 \mathrm{E}+01$ & $-0.94854 \mathrm{E}+01$ & $0.14460 \mathrm{E}+02$ & 1 & 3 & 3 & $-0.10148 \mathrm{E}+00$ \\
\hline 1 & 0 & 0 & $0.27839 E-01$ & $-0.47133 E+00$ & $0.36699 E+00$ & 2 & 0 & 1 & $-0.15475 E+01$ \\
\hline 1 & 0 & 2 & $0.17235 E+01$ & $0.20042 \mathrm{E}+01$ & $-0.43199 E+00$ & 2 & 0 & 3 & $0.22907 \mathrm{E}+01$ \\
\hline 1 & 0 & 4 & $-0.62703 \mathrm{E}+01$ & $-0.57214 \mathrm{E}+01$ & $0.18574 \mathrm{E}+00$ & 2 & 1 & 1 & $0.23260 \mathrm{E}+02$ \\
\hline 1 & 0 & 6 & $0.64590 \mathrm{E}+01$ & $0.57645 E+01$ & $-0.19042 E+00$ & 2 & 1 & 3 & $-0.87984 \mathrm{E}+01$ \\
\hline 1 & 1 & 0 & $-0.81658 \mathrm{E}+01$ & $-0.80954 E+01$ & $0.55393 \mathrm{E}+01$ & 2 & 2 & 1 & $-0.15307 \mathrm{E}+02$ \\
\hline 1 & 1 & 2 & $0.17088 \mathrm{E}+02$ & $0.16657 \mathrm{E}+02$ & $-0.67371 E+01$ & 2 & 2 & 3 & $-0.76504 \mathrm{E}+01$ \\
\hline 1 & 1 & 4 & $-0.47996 \mathrm{E}+02$ & $-0.46863 E+02$ & $0.48886 \mathrm{E}+02$ & 2 & 3 & 1 & $-0.23390 \mathrm{E}+01$ \\
\hline 1 & 1 & 6 & $0.57275 E+02$ & $0.55311 \mathrm{E}+02$ & $-0.56251 E+02$ & 2 & 3 & 3 & $0.10195 \mathrm{E}+02$ \\
\hline 1 & 2 & 0 & $0.18184 \mathrm{E}+02$ & $0.16158 \mathrm{E}+02$ & $-0.10060 \mathrm{E}+02$ & 3 & 0 & 1 & $0.98730 \mathrm{E}+00$ \\
\hline 1 & 2 & 2 & $-0.51812 E+02$ & $-0.50220 \mathrm{E}+02$ & $0.14305 E+02$ & 3 & 0 & 3 & $-0.16671 E+01$ \\
\hline 1 & 2 & 4 & $0.18923 E+03$ & $0.18476 \mathrm{E}+03$ & $-0.13617 \mathrm{E}+03$ & 3 & 1 & 1 & $-0.13498 \mathrm{E}+02$ \\
\hline 1 & 2 & 6 & $-0.20458 E+03$ & $-0.19806 \mathrm{E}+03$ & $0.16139 E+03$ & 3 & 1 & 3 & $0.35067 \mathrm{E}+01$ \\
\hline 1 & 3 & 0 & $-0.10094 \mathrm{E}+02$ & $-0.85514 \mathrm{E}+01$ & $0.49413 E+01$ & 3 & 2 & 1 & $0.53723 E+01$ \\
\hline 1 & 3 & 2 & $0.34890 \mathrm{E}+02$ & $0.33390 \mathrm{E}+02$ & $-0.77503 \mathrm{E}+01$ & 3 & 2 & 3 & $0.12547 \mathrm{E}+02$ \\
\hline 1 & 3 & 4 & $-0.13413 E+03$ & $-0.13068 E+03$ & $0.82669 \mathrm{E}+02$ & 3 & 3 & 1 & $0.44763 E+01$ \\
\hline 1 & 3 & 6 & $0.13902 \mathrm{E}+03$ & $0.13465 E+03$ & $-0.99616 \mathrm{E}+02$ & 3 & 3 & 3 & $-0.12247 \mathrm{E}+02$ \\
\hline 2 & 0 & 0 & $0.37008 \mathrm{E}+00$ & $0.43077 \mathrm{E}+00$ & $-0.16124 \mathrm{E}+00$ & & & & \\
\hline 2 & 0 & 2 & $-0.48335 E+01$ & $-0.43163 E+01$ & $0.73697 \mathrm{E}-01$ & & & & \\
\hline 2 & 0 & 4 & $0.18126 \mathrm{E}+02$ & $0.15820 E+02$ & $0.44922 \mathrm{E}+00$ & & & & \\
\hline 2 & 0 & 6 & $-0.18218 E+02$ & $-0.15788 E+02$ & $-0.11729 E+00$ & & & & \\
\hline 2 & 1 & 0 & $0.15716 \mathrm{E}+02$ & $0.15715 E+02$ & $-0.98606 \mathrm{E}+01$ & & & & \\
\hline 2 & 1 & 2 & $-0.33545 E+02$ & $-0.35751 E+02$ & $0.20672 \mathrm{E}+02$ & & & & \\
\hline 2 & 1 & 4 & $0.94702 \mathrm{E}+02$ & $0.10330 \mathrm{E}+03$ & $-0.11358 E+03$ & & & & \\
\hline 2 & 1 & 6 & $-0.11449 E+03$ & $-0.11960 \mathrm{E}+03$ & $0.11944 \mathrm{E}+03$ & & & & \\
\hline 2 & 2 & 0 & $-0.40103 \mathrm{E}+02$ & $-0.35295 E+02$ & $0.19091 \mathrm{E}+02$ & & & & \\
\hline 2 & 2 & 2 & $0.11148 \mathrm{E}+03$ & $0.11409 E+03$ & $-0.37027 \mathrm{E}+02$ & & & & \\
\hline 2 & 2 & 4 & $-0.40124 \mathrm{E}+03$ & $-0.41823 E+03$ & $0.27773 \mathrm{E}+03$ & & & & \\
\hline 2 & 2 & 6 & $0.43253 E+03$ & $0.44272 E+03$ & $-0.30932 \mathrm{E}+03$ & & & & \\
\hline 2 & 3 & 0 & $0.23819 E+02$ & $0.19974 \mathrm{E}+02$ & $-0.98142 \mathrm{E}+01$ & & & & \\
\hline 2 & 3 & 2 & $-0.77165 E+02$ & $-0.77778 E+02$ & $0.16355 E+02$ & & & & \\
\hline 2 & 3 & 4 & $0.29188 E+03$ & $0.30048 \mathrm{E}+03$ & $-0.15546 \mathrm{E}+03$ & & & & \\
\hline 2 & 3 & 6 & $-0.30135 E+03$ & $-0.30666 \mathrm{E}+03$ & $0.17910 \mathrm{E}+03$ & & & & \\
\hline 3 & 0 & 0 & $0.18566 \mathrm{E}+00$ & $-0.80054 \mathrm{E}-01$ & $0.55516 \mathrm{E}-01$ & & & & \\
\hline 3 & 0 & 2 & $0.40254 \mathrm{E}+01$ & $0.31925 \mathrm{E}+01$ & $0.56762 \mathrm{E}-01$ & & & & \\
\hline 3 & 0 & 4 & $-0.13204 \mathrm{E}+02$ & $-0.11411 \mathrm{E}+02$ & $-0.34231 \mathrm{E}+00$ & & & & \\
\hline 3 & 0 & 6 & $0.13326 \mathrm{E}+02$ & $0.11431 E+02$ & $0.97845 \mathrm{E}-01$ & & & & \\
\hline 3 & 1 & 0 & $-0.76417 \mathrm{E}+01$ & $-0.84732 E+01$ & $0.55027 \mathrm{E}+01$ & & & & \\
\hline 3 & 1 & 2 & $0.16116 \mathrm{E}+02$ & $0.19953 E+02$ & $-0.14710 \mathrm{E}+02$ & & & & \\
\hline 3 & 1 & 4 & $-0.37988 \mathrm{E}+02$ & $-0.53843 \mathrm{E}+02$ & $0.74788 \mathrm{E}+02$ & & & & \\
\hline
\end{tabular}


Table 2. contd.

\begin{tabular}{|c|c|c|c|c|c|c|c|}
\hline$i$ & $j$ & $k$ & $\begin{array}{l}C_{i j k}^{(1 \mathrm{~T}} \\
\text { for tension }\end{array}$ & $\begin{array}{l}C_{i / k}^{|l| b \mid} \\
\text { for bending }\end{array}$ & $\begin{array}{l}C_{i j h}^{\text {IIII }} \\
\text { for torsion }\end{array}$ & $i j k$ & $\begin{array}{l}C_{i j k}^{111 \mathrm{I}} \\
\text { for torsion }\end{array}$ \\
\hline 3 & 1 & 6 & $0.50833 E+02$ & $0.63937 E+02$ & $-0.74985 \mathrm{E}+02$ & & \\
\hline 3 & 2 & 0 & $0.23886 \mathrm{E}+02$ & $0.21101 E+02$ & $-0.10877 E+02$ & & \\
\hline 3 & 2 & 2 & $-0.59707 E+02$ & $-0.67447 \mathrm{E}+02$ & $0.24614 \mathrm{E}+02$ & & \\
\hline 3 & 2 & 4 & $0.20396 \mathrm{E}+03$ & $0.24084 \mathrm{E}+0.3$ & $-0.16937 \mathrm{E}+03$ & & \\
\hline 3 & 2 & 6 & $-0.22429 E+03$ & $-0.25569 E+03$ & $0.18007 E+03$ & & \\
\hline 3 & 3 & 0 & $-0.13916 \mathrm{E}+02$ & $-0.11863 E+02$ & $0.55202 E+01$ & & \\
\hline 3 & 3 & 2 & $0.42030 \mathrm{E}+02$ & $0.46641 \mathrm{E}+02$ & $-0.96793 E+01$ & & \\
\hline 3 & 3 & 4 & $-0.15616 \mathrm{E}+03$ & $-0.17774 \mathrm{E}+0.3$ & $0.88809 \mathrm{E}+02$ & & \\
\hline 3 & 3 & 6 & $0.16211 E+03$ & $0.18102 \mathrm{E}+03$ & $-0.98112 E+02$ & & \\
\hline
\end{tabular}

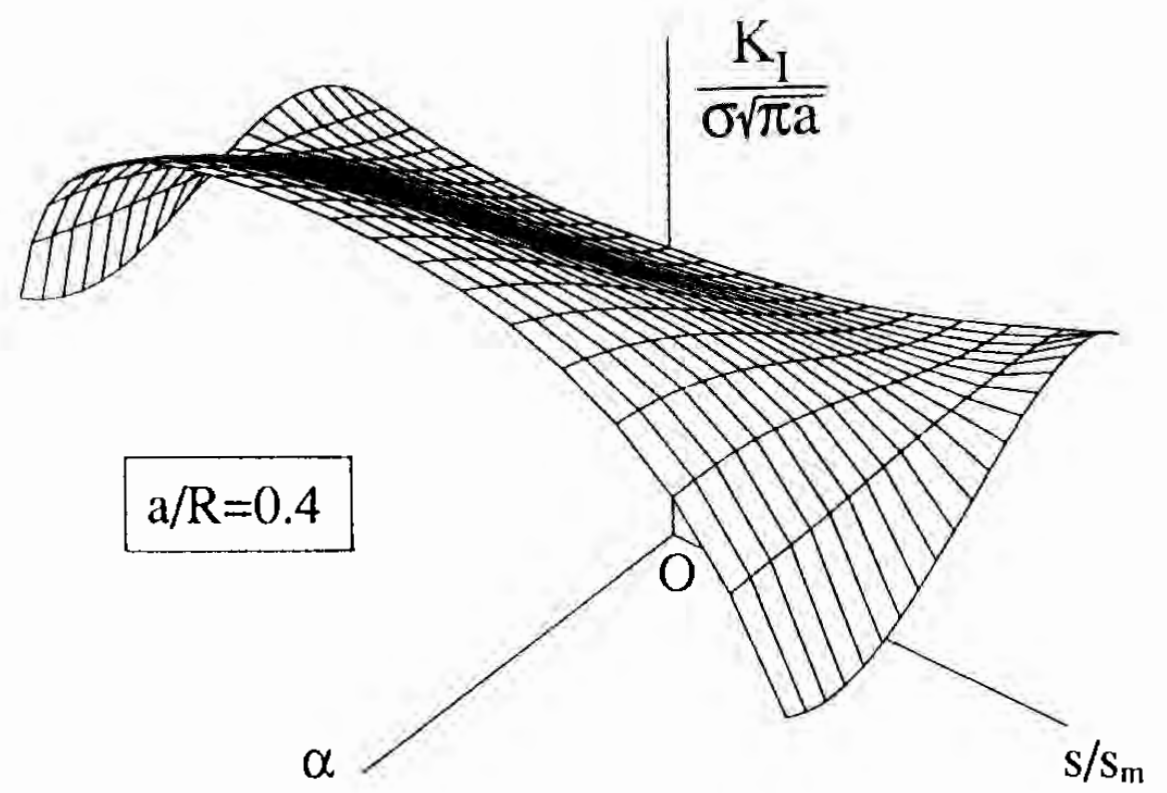

a

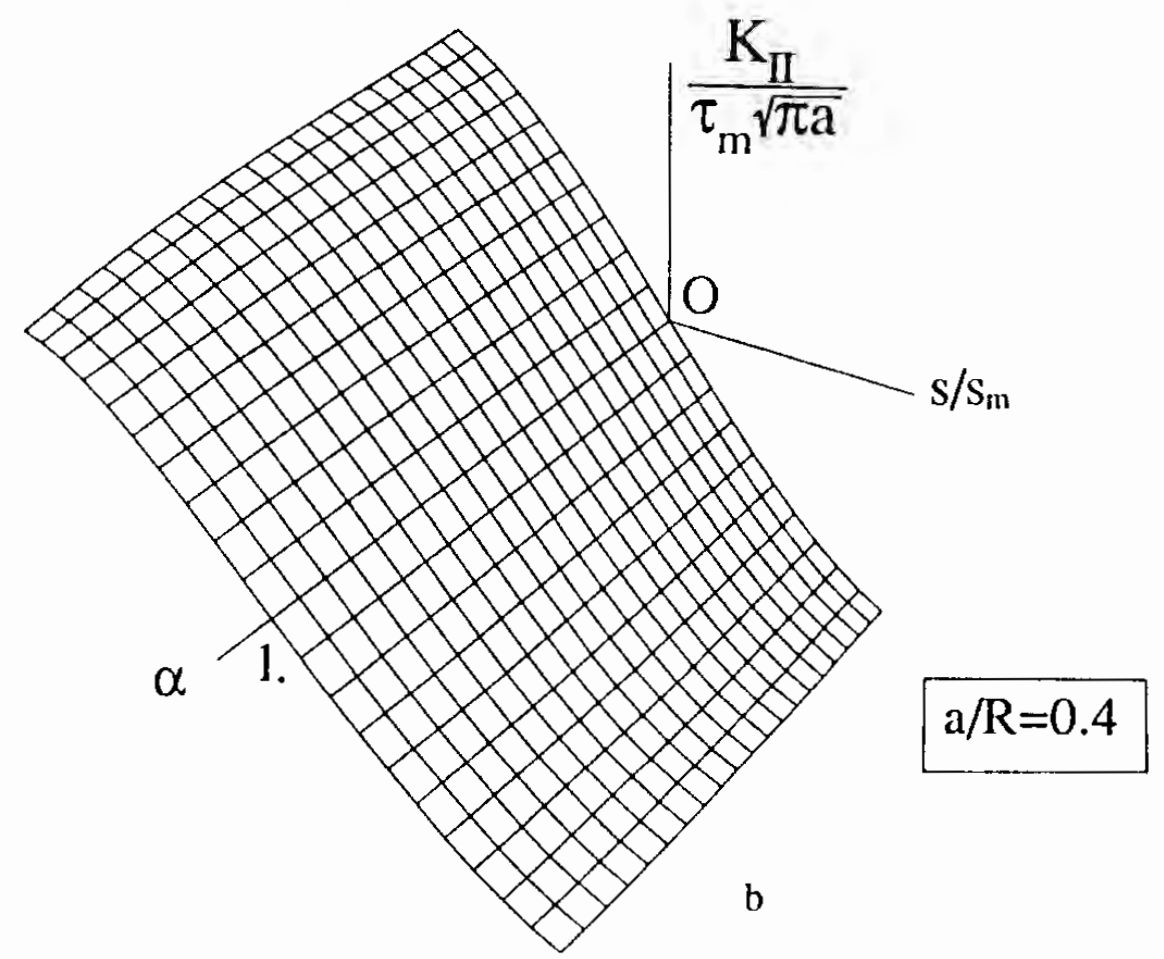

Fig. 10. Stress intensity factors as a function of the crack shape $\alpha$ and the relative abcissa $s ; s_{m}$. (a) Normalized $K_{1}$ in tension. (b) Normalized $K_{1 I}$ in torsion. 


\subsection{Stress intensity factors versus crack depth}

Here, consideration will be limited to the deepest point where the stress intensity factors are given from (4) by putting $s / s_{m}=0$

$$
\frac{K_{\mathrm{A}}}{\sigma \sqrt{\pi a}}=\sum_{i} \sum_{j} \mathrm{C}_{i j 0}\left(\frac{a}{R}\right)^{i} \alpha^{j}
$$

where $K$ stands for $K_{\mathrm{I}}, K_{\mathrm{II}}$ or $K_{\mathrm{III}}$ and $\sigma$ also stands for $\sigma_{m}$ or $\tau_{m}$. Figure 11 shows normalized $K_{\mathrm{l}}$, $K_{\mathrm{III}}$ at the deepest point of the crack resulting from the basic loads - tension, bending and torsion - versus the relative crack depth $a / R$. Factor $K_{\mathrm{II}}$ is not plotted since it is identically zero at $s=0$. For each load there are four $K_{1}$ or $K_{\mathrm{III}}$ curves which relate individually to one crack shape, $\alpha=0, \frac{1}{3}, \frac{2}{3}$ or 1 . It can be seen that the stress intensity factors vary continuously with the crack shape but they are not necessarily monotone functions of the crack depth. For instance in Fig. 11a, the lower and upper curves related respectively to the semi-circular $(\alpha=0)$ and the straight-fronted crack $(\alpha=1)$ show that normalized $K_{\mathrm{IA}}$ increases with crack depth $a$, whereas the intermediate curves $\left(\alpha=\frac{1}{3}\right.$ and $\left.\alpha=\frac{2}{3}\right)$ indicate that $K_{\mathrm{IA}}$, which certainly increases with $a$,
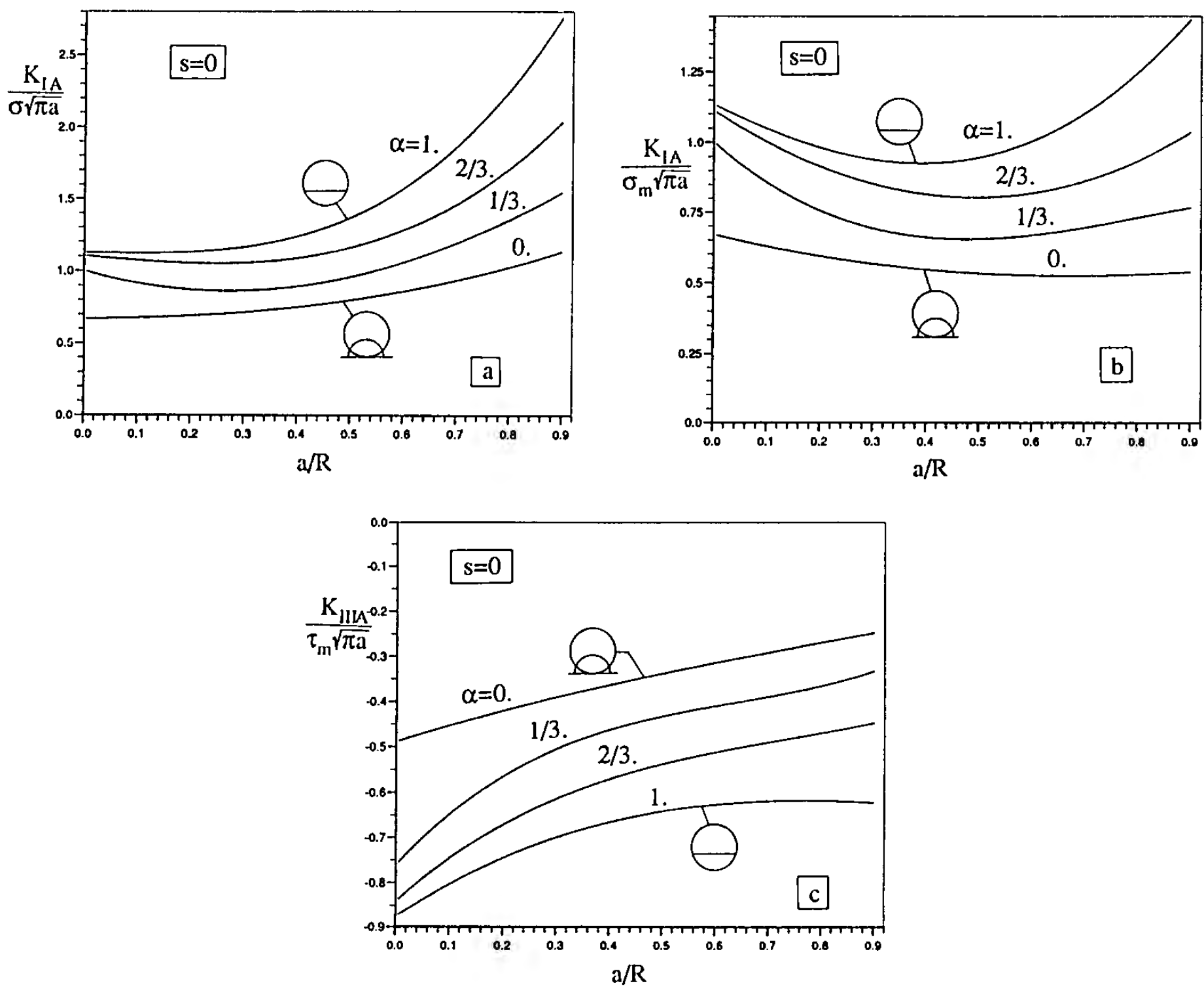

Fig. 11. Normalized stress intensity factors versus the relative crack depth. (a) Tension. (b) Bending. (c) Torsion. 
decreases for small crack depths when normalized by $\sigma \sqrt{(\pi a)}$. It appears from Figs. $11 \mathrm{a}$ and $\mathrm{b}$ that when $a / R$ takes the limit value zero, $K_{1}$ at the deepest point takes almost the same value for the crack shapes $\alpha=1$ and $\frac{2}{3}$. This would mean that, despite the notable change in radius of curvature $-R^{\prime}$ falling off from infinity when $\alpha=1$ (straight-fronted crack) to a finite value when $\alpha=\frac{2}{3}$ - the stress intensity factors remain almost unchanged. In this respect, one can readily establish the limit value for radius $R^{\prime}$ when $a / R$ tends to zero, the radius $R$ of the bar and crack shape $\alpha$ being kept constant

$$
\lim _{a / R \rightarrow 0} R^{\prime}=\frac{\alpha^{2}}{1-\alpha^{2}} R
$$

Relation (6) gives both trivial results - for $\alpha=1, R^{\prime}$ tends to infinity and for $\alpha=0, R^{\prime}$ tends to zero - and rather non-obvious results: for $\alpha=\frac{1}{3} R^{\prime}$ tends to $R / 8=0.125 R$ and for $\alpha=\frac{2}{3} R^{\prime}$ tends to $4 R / 5=0.8 R$, as shown in Fig. 12 .

\subsection{Stress intensity factors along the crack front - Application to the crack growth behaviour problem}

Figure 13 plots the normalized stress intensity factors versus relative abcissa $s / s_{m}$ along the crack front, for the relative crack depth $a / R=0.4$. Figure 13a shows more visibly than Fig. 10 that in the case of a tensile loading, the curvature of the $K_{\mathrm{I}}$ curve changes in sign when passing from the semi-circular crack $(\alpha=0)$ to the straight-fronted one $(\alpha=1)$. Meanwhile, in this instance when $x$ is approximately $\frac{1}{3}$, a crack shape can be observed such that $K_{\mathrm{I}}$ remains virtually constant along the crack front. This means that if the iso- $K_{I}$ criterion is chosen to predict the propagation of cracks created under mode I fatigue, the actual shape is that corresponding to $\alpha=\frac{1}{3}$.

Likewise, Fig. 13b shows that under a bending load the iso- $K_{\mathrm{I}}$ propagation criterion in this instance leads to the shape corresponding to $x=\frac{2}{3}$.

More precisely, for a given crack depth, the crack shape satisfying the iso- $K_{1}$ criterion can be computed in the following manner. Bearing in mind that $R, \alpha$ and $\sigma$ are constant, deriving

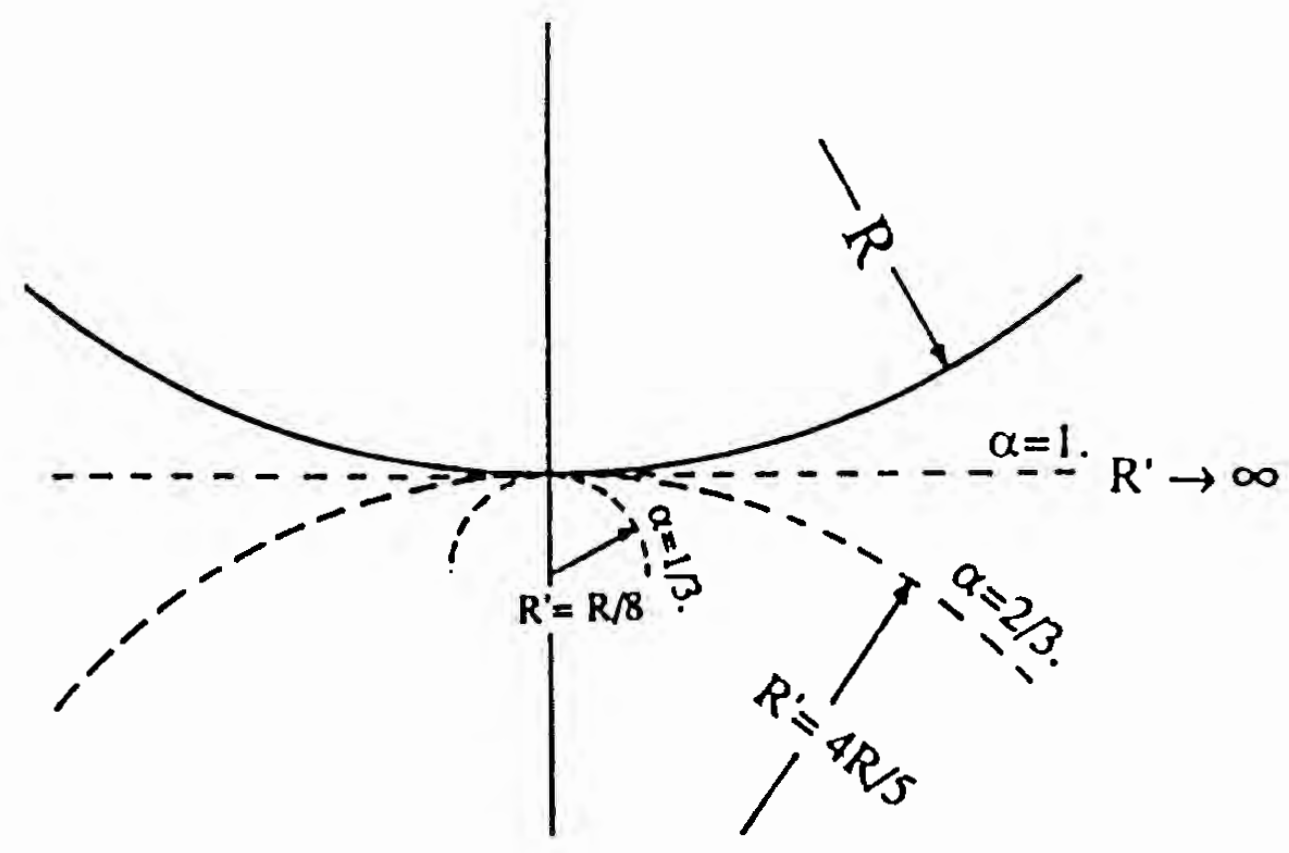

Fig. 12. Limit values of crack radius $R^{\prime}$ for very shallow surface cracks. 

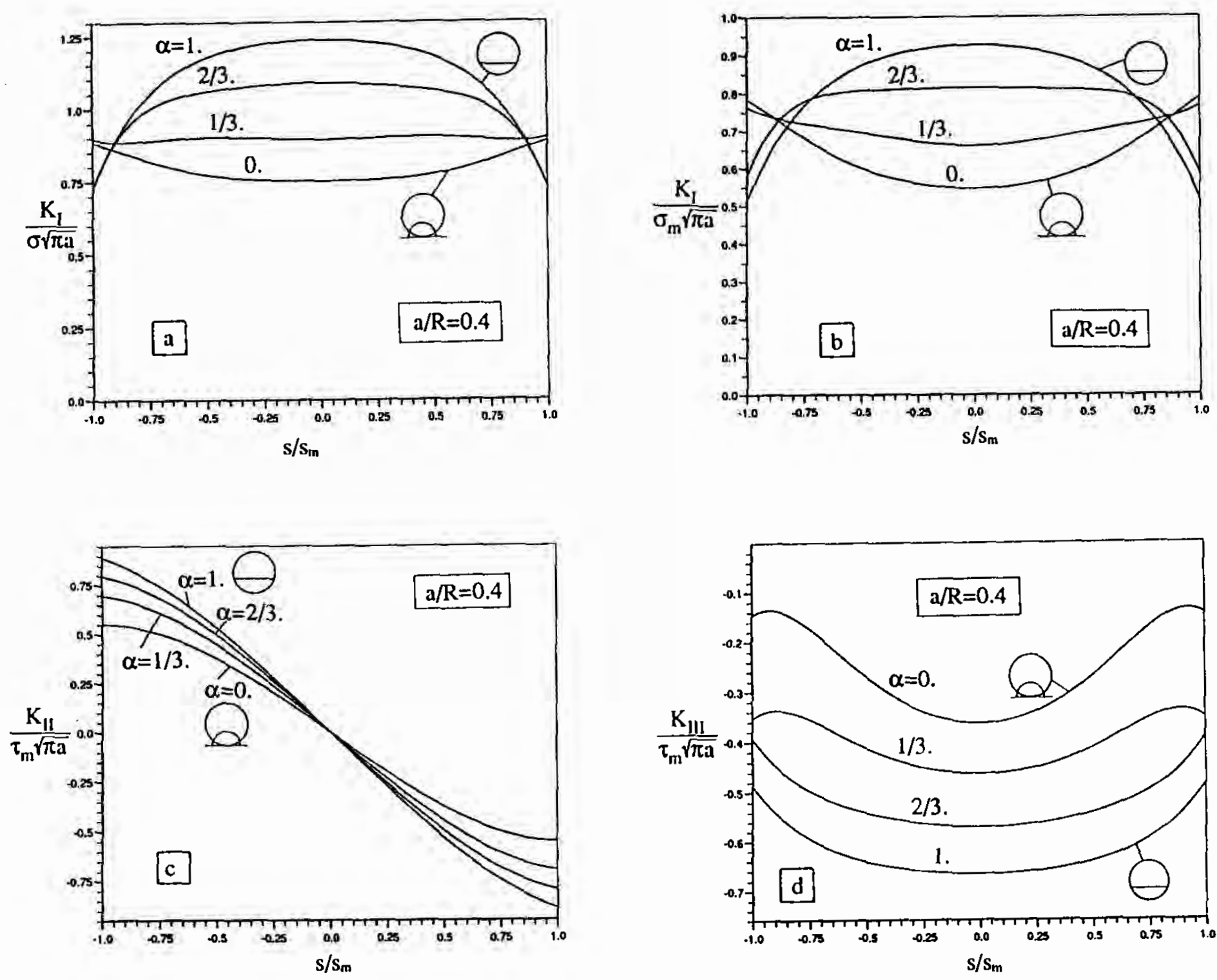

Fig. 13. Normalized stress intensity factors versus the relative abcissa on the crack front. (a) $K_{\mathrm{I}}$ in tension. (b) $K_{1}$ in bending. (c) $K_{\mathrm{II}}$ in torsion. (d) $K_{\mathrm{III}}$ in torsion.

expression for $K_{\mathrm{I}}$ given in (4) with respect to the relative abcissa $s / s_{m}$ yields

$$
\frac{\partial K_{1}}{\partial\left(\frac{s}{s_{m}}\right)}=\sigma \sqrt{\pi a} \sum_{i} \sum_{j} \sum_{k \geqslant 1} k C_{i j k}\left(\frac{a}{R}\right)^{i} \alpha^{j}\left(\frac{s}{s_{m}}\right)^{k-1} .
$$

As it is clear that the derivative of $K_{I}$ cannot be identically equated to zero for all values of $s / s_{m} \in[-1,1]$, the solution crack shape $\alpha$ is such that it minimizes $\max \left\|\partial K_{1} / \partial\left(s / s_{m}\right)\right\|$, i.e. $\alpha$ is the solution of the min-max condition

$$
\min _{\alpha \in[0.1]} \max _{s / s_{m} \in[-1,1]}\left\|\sum_{i} \sum_{j} \sum_{k \geqslant 1} k C_{i j k}\left(\frac{a}{R}\right)^{i} \alpha^{j}\left(\frac{s}{s_{m}}\right)^{k-1}\right\| .
$$

In order to outline the crack propagation during mode I fatigue, $(8)$ is approximately solved and the results obtained are within 5 percent accuracy. Table 3 lists the solution crack shapes $\alpha$ for the relative crack depths $a / R$ considered in this paper.

Figure 14 compares the crack shapes predicted by the iso- $K_{1}$ criterion with those of the cracks intersecting the free lateral surface at $90^{\circ}$ angles. The latter cracks will be referred to, for brevity, 
Table 3 . Crack shapes verifying the iso- $K_{\text {, }}$ criterion. Comparison with right angle cracks

\begin{tabular}{llllllll} 
& $a R$ & 0.04 & 0.12 & 0.24 & 0.40 & 0.60 & 0.85 \\
\hline $\begin{array}{l}\text { Iso- } K_{\mathrm{I}} \\
\text { criterion in } \\
\text { TENSION }\end{array}$ & $x$ & 0.03 & 0.06 & 0.14 & 0.30 & 0.42 & 0.70 \\
$\begin{array}{l}\text { Iso- } K_{\mathrm{I}} \\
\text { criterion in } \\
\text { BENDING }\end{array}$ & $R^{\prime} R$ & 0.048 & 0.147 & 0.331 & 0.694 & 1.172 & 2.940 \\
$\begin{array}{l}\text { Right } \\
\text { intersecting }\end{array}$ & $R^{\prime} R$ & 0.051 & 0.168 & 0.481 & 1.028 & 1.756 & 3.697 \\
$\begin{array}{l}\text { angle } \\
\text { criterion }\end{array}$ & $x$ & 0.003 & 0.02 & 0.07 & 0.17 & 0.36 & 0.73 \\
\hline
\end{tabular}
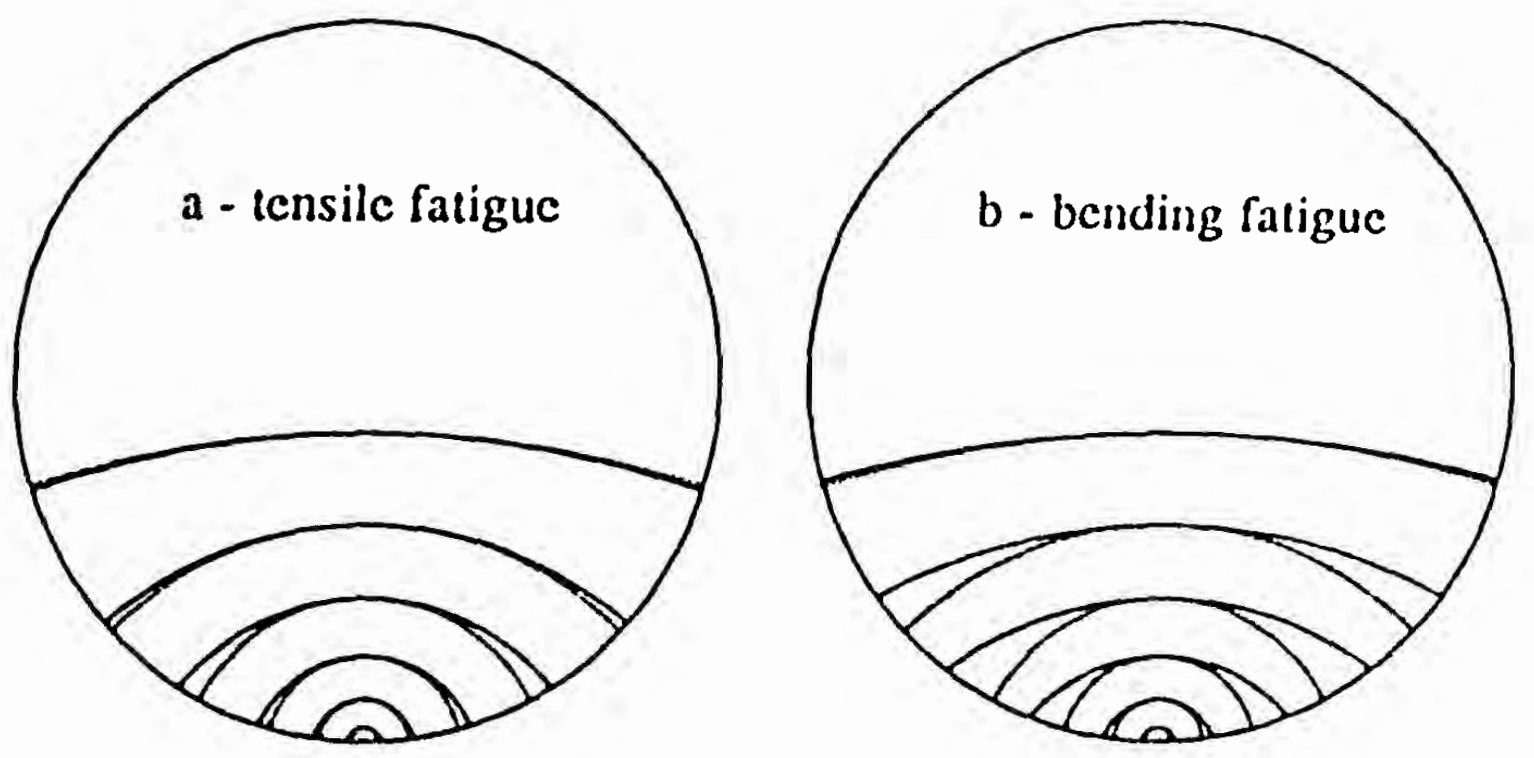

iso- $\mathrm{K}_{\mathrm{l}}$ critcrion

\section{$\ldots$ right intersecting angle criterion $\left(\psi=90^{\circ}\right)$}

Fig. 14. Prediction of crack growth under mode I fatigue.

as $90^{\circ}$ (intersecting) angle cracks. For such cracks, $\psi=90^{\circ}$ (Fig. 1) and one can readily prove that the crack radius $R^{\prime}$ is related to the radius $R$ of the bar and the crack depth a by the relation

$$
R^{\prime}=\frac{a(2 R-a)}{2(R-a)} .
$$

It can be observed that the difference between iso- $K_{1}$ cracks and 90 angle ones is fairly small in the case of tension (Fig. 14a) whereas this difference becomes notable for medium-sized cracks under bending (Fig. 14b). This would mean that in tensile load fatigue tests, cracks verifying the iso- $K_{\mathrm{I}}$ criterion are almost $90^{\circ}$ angle cracks, while in bending fatigue tests this is true only for cracks with very small or very large depths. It should be remembered that this assessment has been made with $r$ ' equal to 0.3 , and that the study of the influence of Poisson's ratio on the shape of cracks created by fatigue, which would not be negligible. is beyond the scope of this work. 
Figures 15,16 show the change in shape as the crack depth increases during the propagation. At the crack initiation, the crack is almost semi-circular. The further it grows up, i.e. the more the crack depth increases, the more it resembles a straight-fronted crack. Also represented in Figs. 15, 16 are the following stress intensity factors for a $90^{\circ}$ angle crack: $K_{\mathrm{I}}$ at the deepest point 1 (in this case it is the minimum $K_{\mathrm{I}}$ on the crack front) and the average $K_{\mathrm{I}}$ denoted by $\overline{\boldsymbol{K}}_{\mathrm{I}}$

$$
\frac{\bar{K}_{\mathrm{I}}}{\sigma \sqrt{\pi a}}=\frac{1}{2 s_{m}} \int_{-s_{m}}^{+s_{m}} \frac{K_{\mathrm{I}}}{\sigma \sqrt{\pi a}} \mathrm{~d} s=\frac{1}{2} \int_{-1}^{+1} \frac{K_{\mathrm{I}}}{\sigma \sqrt{\pi a}} d\left(\frac{s}{s_{m}}\right)=\sum_{i} \sum_{j} \sum_{k} \frac{1}{k+1} C_{i j k}^{(\mathrm{l})}\left(\frac{a}{R}\right)^{i} \alpha^{j} .
$$

It is clearly shown in Fig. 15 that for $90^{\circ}$ angle cracks under tension, $K_{\mathrm{IA}}$ is approximately $\overline{\boldsymbol{K}}_{\mathrm{I}}$ (the curves e and $f$ are quite the same) and again one can recognize that $90^{\circ}$ angle cracks verify the iso- $K_{1}$ criterion. On the other hand, Fig. 16 shows that in the bending case, $90^{\circ}$ angle cracks verify the iso- $K_{\mathrm{I}}$ criterion only for $a / R \approx 0$ and $a / R \approx 0.9$.

Figures $13 \mathrm{c}$ and $13 \mathrm{~d}$ show the stress intensity factors $K_{\mathrm{II}}$ and $K_{\mathrm{III}}$ arising from a twisting moment applied at the ends of the bar. As already mentioned, $K_{\mathrm{II}}$ varies almost as a linear function of the curvilinear abcissa $s$. On the other hand, for all crack shapes the absolute value of $K_{\mathrm{III}}$ is maximal at the deepest point. In any case, the aspect of $K_{\mathrm{II}}$ and $K_{\mathrm{III}}$ curves are little influenced by the crack shape, contrary to what happens to $K_{\mathrm{I}}$. Regarding the crack propagation behaviour with the presence of anti-plane shear, experimental investigations in pure mode III by [27] clearly show that the crack no longer grows by extending in its own plane but by

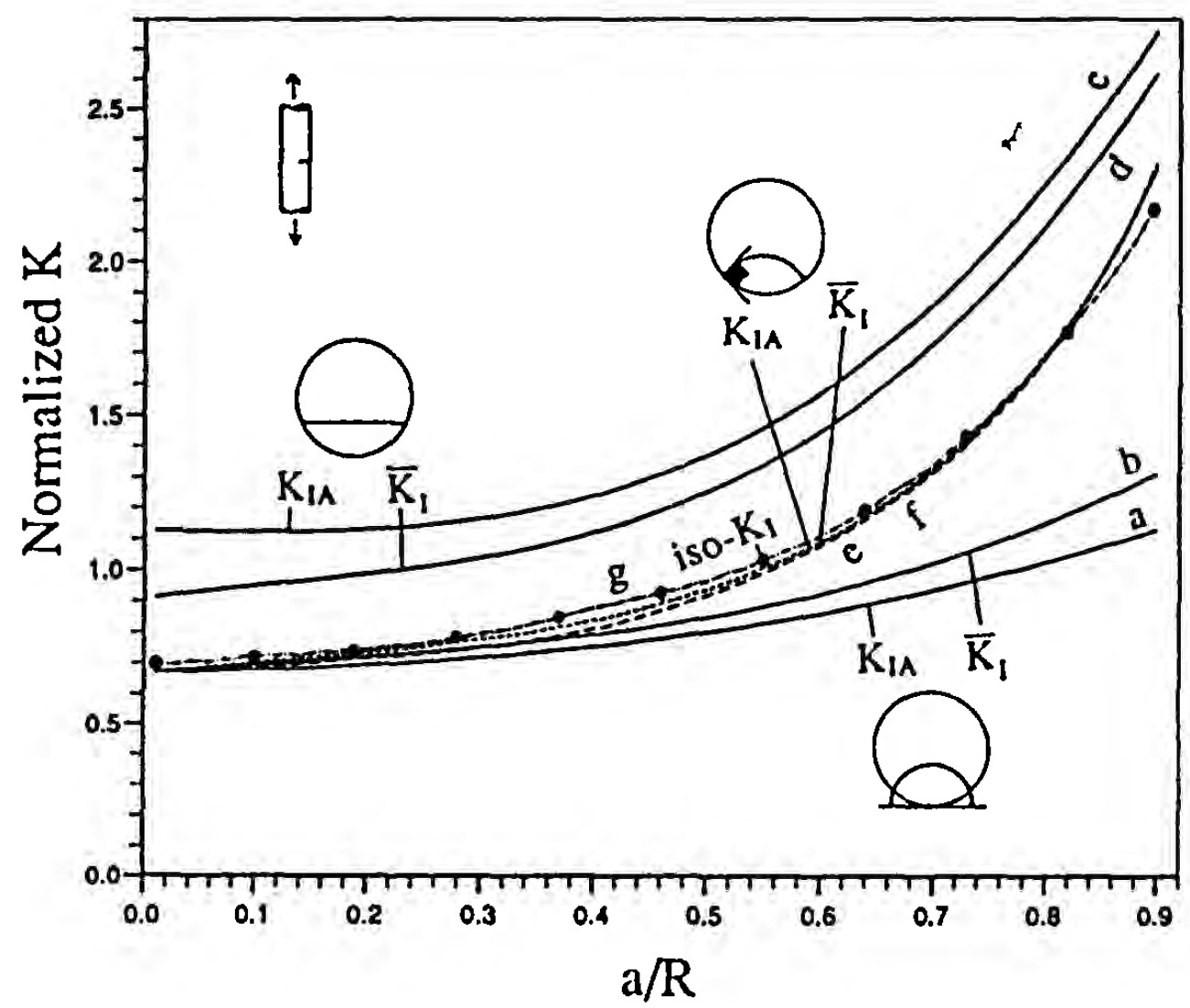

Fig. 15. Normalized $K_{\mathrm{I}}$ in tension at the deepest point and average normalized $K_{1}$ for different crack shapes. Comparison with $K_{\mathrm{I}}$ computed from the iso- $K_{\mathrm{I}}$ criterion. (a) $K_{\mathrm{I}}$ at the deepest point for semi-circular cracks. (b) Average $K_{1}$ for semi-circular cracks. (c) $K_{\mathrm{I}}$ at the deepest point for straight-fronted cracks. (d) Average $K_{\mathrm{I}}$ for straight-fronted cracks. (e) $K_{\mathrm{I}}$ at the deepest point for right angle cracks. (f) Average $K_{\mathrm{I}}$ for right angle cracks. (g) $K_{\mathrm{I}}$ for cracks verifying the iso- $K_{\mathrm{I}}$ criterion. 


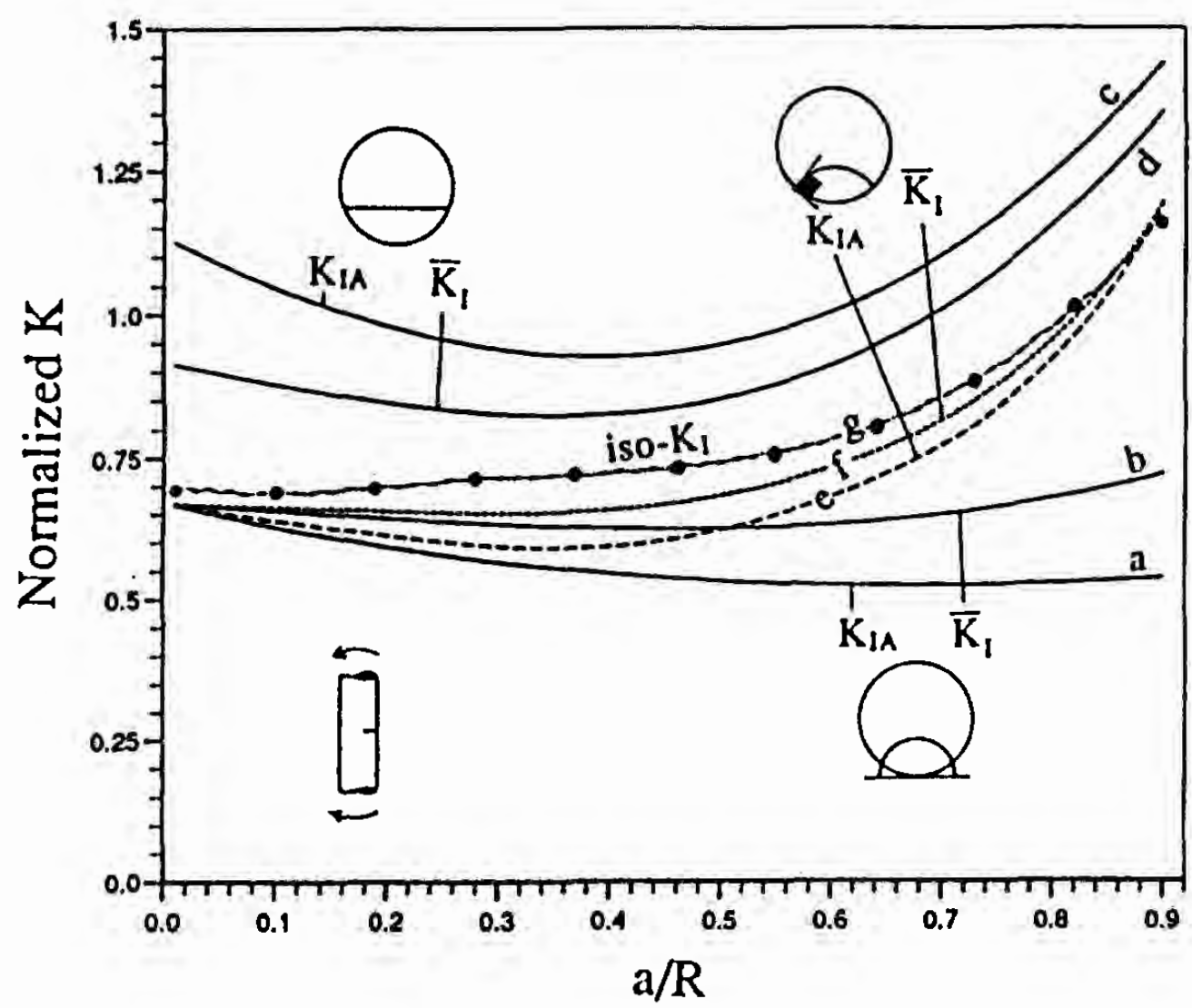

Fig. 16. Analogous to Fig. 15, the loading is now a bending.

generating multiple penny-shaped cracks which straddle the original crack front. The study of the crack deviation in a bar under torsion must be even more difficult at the points on the front, where $K_{\mathrm{II}}$ and $K_{\mathrm{III}}$ take comparable values. Similarly, under combined tensile and anti-plane shear loading (mode I + III), the crack grows by developing multiple lancelike fracture facets surrounding the crack front, as shown in [28]. These observations should be taken into account when the crack instability is studied under general loading conditions.

Lastly, it is noteworthy that the provided stress intensity factors values are valid only over about 80 percent of the crack front length. The $K$ values for $s / s_{m}$ approaching \pm 1 are affected by phenomena extraneous to the present work, such as the vicinity of the surface terminal points $B$ or $B^{\prime}$ (Fig. 1) that modifies the crack tip singularity. Also, the poor refinement of the finite element mesh around these zones must lower the accuracy of the numerical results. In any event, the results obtained in [29] prove that the crack tip singularity at the surface point depends on the Poisson ratio $v$ and the terminal point incident angle $\psi$ (see Fig. 1) between the crack front and the surface line $B B^{\prime}$. For a given value of $\psi$, there exists a limiting value of $\psi$ for which the stress intensity factor $K_{\mathrm{I}}$ tends to a non zero finite value. If $\psi$ is less than this limit value, $K_{1}$ falls off to zero and if $\psi$ is greater, $K_{I}$ becomes infinite. In both cases $K_{1}$ classically defined loses its physical meaning.

\section{Comparison with theoretical results}

No theoretical results are available for surface cracks in round bars. However, stress intensity factors at the deepest point (point A in Fig. 1) of very shallow straight-fronted cracks can be 
effectively compared with analytical solutions for the single-edge crack in the half-space. This is due to the likeness between the latter geometry and the crack configuration viewed from point $A$ when $a / R$ tends to zero.

\subsection{Bar under tension}

The theoretical value for an edge crack of length $a$ under a uniform pressure $\sigma$ is given by Koiter [30]

$$
K_{\mathrm{I}}=1.1215 \sigma \sqrt{(\pi a)}
$$

On the other hand, making $a / R$ tend to zero in (5) gives

$$
\lim _{a / R \rightarrow 0} \frac{K_{\mathrm{IA}}}{\sigma \sqrt{\pi a}}=\sum_{j} C_{0 j 0}^{(\mathrm{It})} \alpha^{j}
$$

which yields the limit value of normalized $K_{\mathrm{I}}$ at deepest point A of straight-fronted cracks

$$
\lim _{a / R \rightarrow 0, \alpha=1} \frac{K_{\mathrm{IA}}}{\sigma \sqrt{\pi a}}=\sum_{j} C_{0 j 0}^{(\mathrm{It})}=1.126
$$

This value agrees well with the theoretical value (11) within an error of +0.4 percent. As regards the limit value of $K_{\mathrm{IA}}$ for semi-circular cracks when $a / R$ tends to zero, one expects it to be greater than the theoretical value $2 / \pi=0.6366$ for the penny-shaped crack embedded in the infinite body, as is easily explained by the presence of the free lateral surface of the bar which must allow a wider crack opening, thus a greater $K_{\mathrm{IA}}$. Indeed, here the limit value for semi-circular cracks is found to be 0.668 , which is about 5 percent higher than the foregoing analytical value $2 / \pi$.

Further, deriving expression (5) gives

$$
\frac{\partial}{\partial(a / R)}\left(\frac{K_{\mathrm{IA}}}{\sigma \sqrt{\pi a}}\right)=\sum_{i \geqslant 1} \sum_{j} i C_{i j 0}^{\mathrm{( \textrm {ll } )}}\left(\frac{a}{R}\right)^{i-1} \alpha^{j} .
$$

Hence the slopes at $a / R=0$ of the normalized $K_{\mathrm{IA}}$ curves are

$$
\begin{aligned}
& \lim _{a / R \rightarrow 0, \alpha=0} \frac{\partial}{\partial(a / R)}\left(\frac{K_{\mathrm{IA}}}{\sigma \sqrt{\pi a}}\right)=C_{100}^{(\mathrm{Il})}=0.028=\tan ^{-1} 2^{\circ} \\
& \lim _{a / R \rightarrow 0, \alpha=1} \frac{\partial}{\partial(a / R)}\left(\frac{K_{\mathrm{IA}}}{\sigma \sqrt{\pi a}}\right)=\sum_{j} C_{1 j 0}^{(\mathrm{Il})}=-0.048=\tan ^{-1}\left(-3^{\circ}\right)
\end{aligned}
$$

respectively for semi-circular and straight-fronted cracks. These are quite small values that compare well with the zero slope drawn from relation $(11), \lim \partial\left(K_{\mathrm{I}} / \sigma \sqrt{\pi a}\right) / \partial(a / R)=0$. 


\subsection{Bar under bending}

From Table 2 one obtains the limit value of normalized $K_{\mathrm{I}}$ at deepest point $\mathrm{A}$ of straight-fronted cracks in the case of bending load

$$
\lim _{a / R \rightarrow 0 . \alpha=1}\left(\frac{K_{\mathrm{IA}}}{\sigma_{m} \sqrt{\pi a}}\right)=\sum_{j} C_{0 j 0}^{(\mathrm{lb})}=1.135
$$

This agrees well with Koiter's theoretical value [30] which is also valid in the bending case, within an error of +1 percent. Note that the slopes at $a / R=0$ for semi-circular and straight-fronted cracks can also be computed in a similar way as in tensile loading

$$
\begin{aligned}
& \lim _{a: R \rightarrow 0 . x=0} \frac{\partial}{\partial(a / R)}\left(\frac{K_{\mathrm{IA}}}{\sigma_{m} \sqrt{\pi a}}\right)=C_{100}^{(\mathrm{b})}=-0.471=\tan ^{-1}(-25), \\
& \lim _{a / R \rightarrow 0, x=1} \frac{\partial}{\partial(a / R)}\left(\frac{K_{\mathrm{IA}}}{\sigma_{m} \sqrt{\pi a}}\right)=\sum_{j} C_{1 j 0}^{(\mathrm{bb})}=-0.961=\tan ^{-1}\left(-44^{\prime}\right),
\end{aligned}
$$

although no easy comparison with theoretical values is possible to our knowledge.

\subsection{Bar under torsion}

Lastly, consider an edge crack of length $a$ in the semi-infinite space, subjected to a uniform shear $\tau$ parallel to the crack front. The analytical result for the problem is given in [31]

$$
K_{1 I I}=-\tau \sqrt{(\pi a)}
$$

Applying the same reasoning to (5) as in proving (13), one obtains

$$
\lim _{a / R \rightarrow 0 . x=1} \frac{K_{\mathrm{IIIA}}}{\tau_{m} \sqrt{\pi a}}=\sum_{j} C_{0 j 0}^{(\mathrm{III})}=-0.875
$$

This value is 13 percent higher than the theoretical value -1 . The difference can be accounted for by the fact that the shear is in-plane stress. In Fig. 17, the hatched area represents the

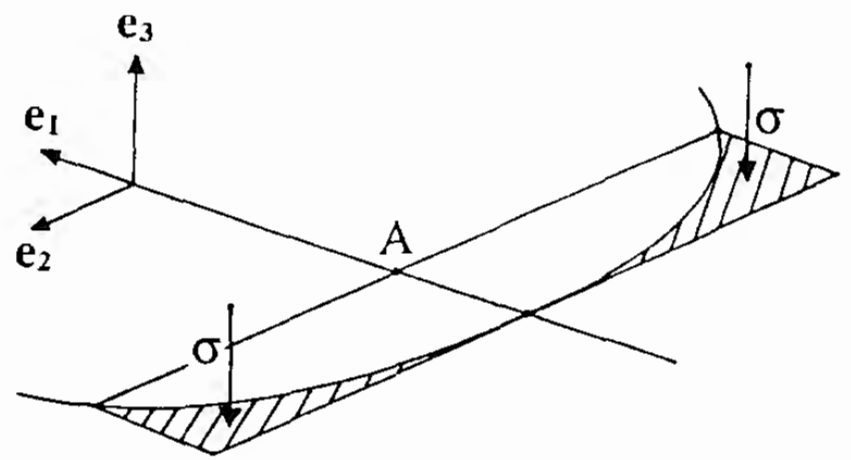

$\mathbf{a}$

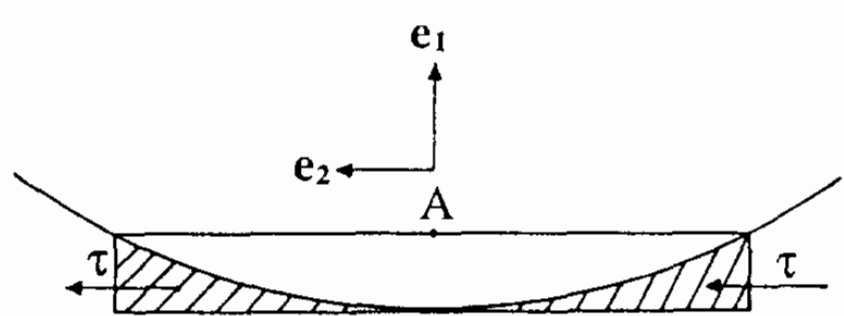

b

Fig. 17. Difference between the problem of a crack in a round bar and that of an edge crack in the semi-infinite body. 
difference between the problem of a shallow crack in a round bar and that of an edge crack in the semi-infinite medium. In mode I problems, the applied stresses are normal to this area and their effect can be neglected around the deepest point A of interest. On the contrary, in mode III problems the stresses are parallel to the crack front, hence they may have some influence on $K_{\text {III }}$ at point $\mathrm{A}$ though applied on an area geographically remote.

\section{Comparison with experimental results}

Available results in the literature are mainly concerned with mode I and points A, B on the crack fruit (Fig. 1). Sometimes, $K_{I}$ is even assumed to be constant on the crack front so that only the average value is considered. Therefore, the somparison with either experimental or numericai results can be made only in the tension and bending cases. Also, as discussed above, stress intensity factor values at the surface terminal point $B$ will be discarded and only the values at the deepest point $\mathrm{A}$ - or the average values whenever they are given - are compared. We shall denote the diameter of the bar by $D, D=2 R$.

\subsection{Bar under tension}

Figure 18 compares $K_{I}$ value of the present work with other authors' experimental values which are summarized below.

\section{- Straight-fronted cracks}

By the compliance method Daoud et al. [7] give the average normalized $\overline{\boldsymbol{K}}_{\mathbf{I}}$ for straight-fronted crack

$$
\frac{\bar{K}_{\mathrm{I}}}{\sigma \sqrt{\pi a}}=\frac{\sqrt{\pi}}{4\left(1-\frac{a}{D}\right)^{1 / 4}} \sqrt{8.61-52.47 \frac{a}{D}+167.1\left(\frac{a}{D}\right)^{2}}, \quad 0.1 \leqslant a / D \leqslant 0.5 .
$$

Table 4 gives the normalized $K_{1}$ at the deepest point A by photoelasticity determined by Astiz et al. [8]. In fact, the value 1.85 corresponding to $a / D=0.45$ in this table will not be retained here as it is unreliable according to [8].

Bush [9] gives the compliance expression $\mathrm{c}$ in terms of the relative crack depth $a / D$

$$
c=0.0598723+0.2680344\left(\frac{a}{D}\right)^{2.8}+0.2508381\left(\frac{a}{D}\right)^{3}+39.43071\left(\frac{a}{D}\right)^{12},
$$

which provides the average normalized $\bar{K}_{1}$ via the following relation

$$
\frac{\bar{K}_{\mathrm{I}}}{\sigma \sqrt{\pi a}}=\frac{\sqrt{\pi}}{4 \sqrt{\frac{a}{D}}}\left(\frac{E}{1-v^{2}} \frac{D}{4} \frac{1}{\left[a / D-(a / D)^{2}\right]^{0.5}} \frac{d c}{d(a / D)}\right)^{0.5}
$$




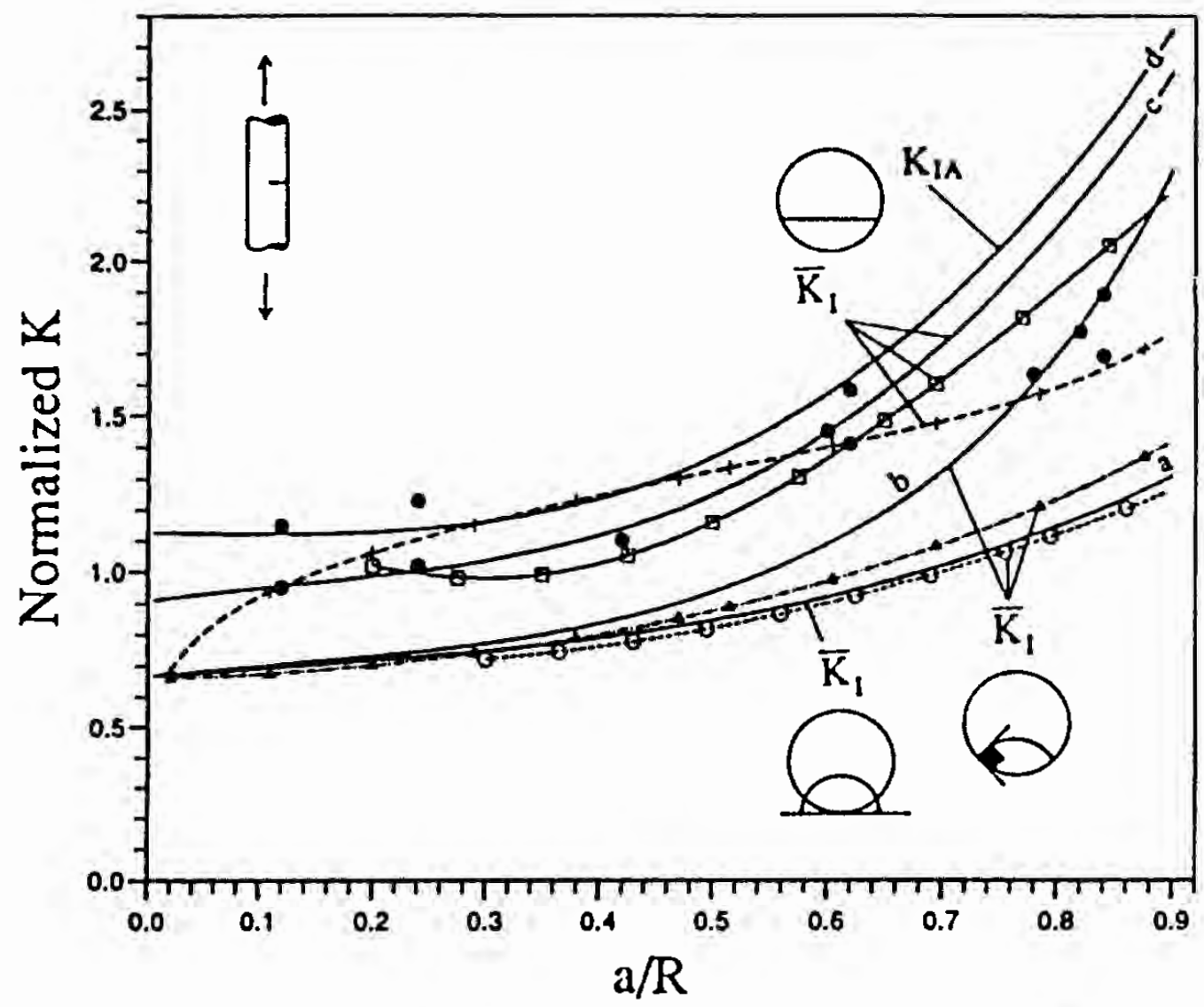

Fig. 18. Comparison with experimental results for $K_{\mathrm{r}}$ in tension: $\boxminus-$ : Daoud et al. [7]. : Astiz et al. [8]. -+-+ Bush [9]. $-\bigcirc \bigcirc-:$ Wilhem et al. [4]. - - : Forman et al. [5], [32]. - : Present results (a) Average $K_{1}$ for semi-circular cracks. (b) Average $K_{\mathrm{I}}$ for right angle cracks. (c) Average $K_{\mathrm{I}}$ for straight-fronted cracks. (d) $K_{\mathrm{I}}$ at the deepest point for straight-fronted cracks.

The unity for compliance $c$ in (23) is $10^{-6} \mathrm{in} / \mathrm{lbf}$, Young's modulus in (24) is $10.6 \times 10^{6} \mathrm{psi}$, and $D=3$ in. Attention should be drawn to the fact that in [9] the Poisson ratio is 0.32 and not 0.3 as assumed throughout this paper. However, the results are expected to be close enough to be comparable.

- Cracks intersecting the lateral surface at right angles $\left(\psi=90^{\circ}\right.$, Fig. 1$)$

A special fatigue marking technique to outline the crack propagating allowed Wilhem et al. [4] to express the normalized $K_{\mathrm{I}}$ for right angle cracks, constant along the crack front, as

$$
\frac{\bar{K}_{1}}{\sigma \sqrt{\pi a}}=0.690-0.197 \frac{a}{D}+2.394\left(\frac{a}{D}\right)^{2}+1.965\left(\frac{a}{D}\right)^{3}, \quad 0.15<a / D<0.45
$$

Experiments conducted on fatigue cracks led Forman et al. [5], [32] to approximate the same quantity as

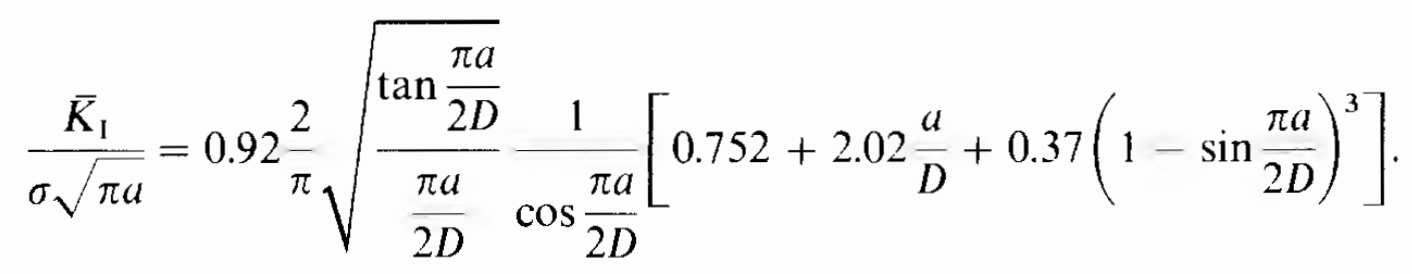

(26) is reported as having good accuracy for $a / D \ll 1$, reasonable accuracy for $a / D<\frac{1}{2}$. 
Table 4. Normalized $K_{\mathrm{l}}$ at the deepest point of straight-fronted cracks [8]

\begin{tabular}{llllllllllll}
\hline$a / D$ & 0.45 & 0.21 & 0.30 & 0.39 & 0.41 & 0.46 & & 0.06 & 0.12 & 0.31 & 0.42 \\
\hline$K_{\mathrm{IA}} / \sigma \sqrt{(\pi a)}$ & 1.85 & 1.10 & 1.45 & 1.63 & 1.77 & 1.91 & 1st series & 1.15 & 1.02 & 1.58 & 1.89 \\
& & & & & & & 2nd series & 0.95 & 1.23 & 1.41 & 1.69 \\
\hline
\end{tabular}

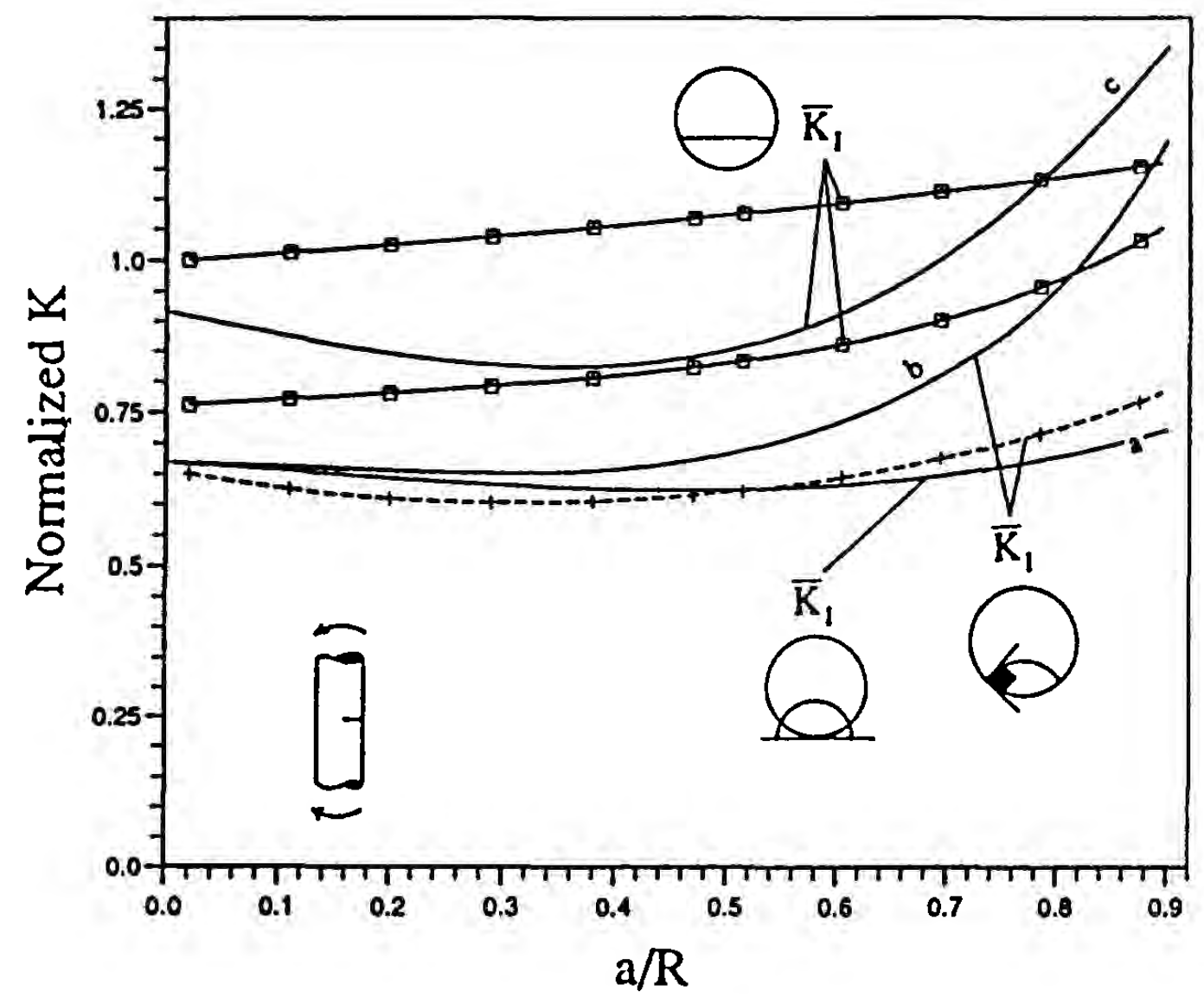

Fig. 19. Comparison with experimental results for $K_{1}$ in bending: $-\square-$ : Bush [6]. -+-+- : Forman et al. [5]. — : Present results (a) Average $K_{1}$ for semi-circular cracks. (b) Average $K_{1}$ for right angle cracks. (c) Average $K_{1}$ for straight-fronted cracks.

Figure 18 shows a good agreement between different results for small crack depths. Regarding large crack depths, other workers' results relating to $90^{\circ}$ angle cracks are rather closer to present $K_{1}$ for semi-circular cracks. As for straight-fronted cracks, the discrepancy becomes notable for large crack depths too.

\subsection{Bar under bending}

\section{- Straight-fronted cracks}

By means of compliance measurements Bush [6] provides the following equation for calculating the average stress intensity factor in the case of bending load

$$
\frac{\bar{K}_{1}}{\sigma_{m} \sqrt{\pi a}}=\frac{\sqrt{\pi}}{32 \sqrt{\frac{a}{D}}}\left(\frac{E}{1-v^{2}} \frac{D^{3}}{l^{2}} \frac{1}{\left[a / D-(a / D)^{2}\right]^{0.5}} \frac{d c}{d(a / D)}\right)^{0.5},
$$


where the compliance $c$ is determined by either expression

$$
\begin{array}{ll}
c=4.338749+23.66921\left(\frac{a}{D}\right)^{2.5}+131.0767\left(\frac{a}{D}\right)^{7}\left(10^{-6} \mathrm{in} / \mathrm{lbf}\right), \\
c=0.2910587+2.54535\left(\frac{a}{D}\right)^{2.5} & \left(10^{-6} \mathrm{in} / \mathrm{lbf}\right) .
\end{array}
$$

Here again, $E=10.6 \times 10^{6}$ psi. and $v=0.32$. Relation (28) is used with diameter $D=3$ in, relation (29) with $D=6$ in. In both relations, length $l$ is about $10 \mathrm{in}$.

- Cracks intersecting the lateral surface at right angles

Experiments conducted on fatigue cracks led Forman et al. [5] to the following approximate expression for the normalized $K_{1}$ constant along the crack front

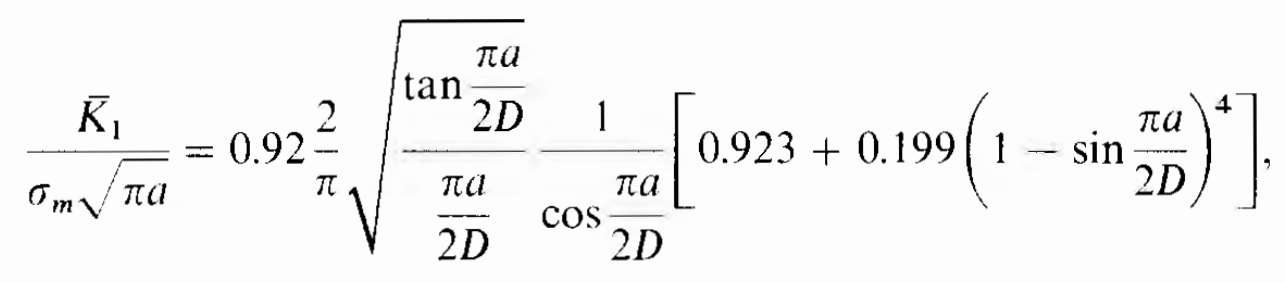

with the same accuracy reported above for the bar under tension.

- The comparison with all the available results for the bar under bending are shown in Fig. 19 . For $90^{\circ}$ angle cracks, a good agreement is observed at small crack depths only. As the crack depth increases, the experimental curve is rather closer to ours computed for semi-circular cracks. This remark agrees with Caspers et al.'s [19] following which 'the theory of perpendicular angles between crack front and shaft circumference seems to be approximately correct for pure bending up to an $a / R$-ratio of 1.0 , but does not seem to be so applicable for tension, especially for increasing $a / R$-ratios'.

Concerning the straight-fronted cracks, the computed curve is within the range of Bush's experimental ones. Lastly, it should be mentioned that straight-fronted cracks do not exist naturally and they are actually very difficult to obtain in experimental works. In most cases, a sharp notch was machined to simulate the crack [6-9]. As the machined notch must be wider for a larger notch depth, it is unlikely to be comparable with a real crack. This should explain why the results agree less for large crack depths.

\section{Comparison with numerical results}

Here again, the comparisons are made in tension and bending cases. Moreover, only the $K_{1}$ at the deepest point or its mean value is reported.

\subsection{Bar under tension}

Figure 20 shows all the numerical results for the case of a tensile load. Astiz [18] considered semi-elliptic cracks with axes $a, b$. The normalized $K_{\mathrm{I}}$ factor at the deepest point $\mathrm{A}$ is given as a 


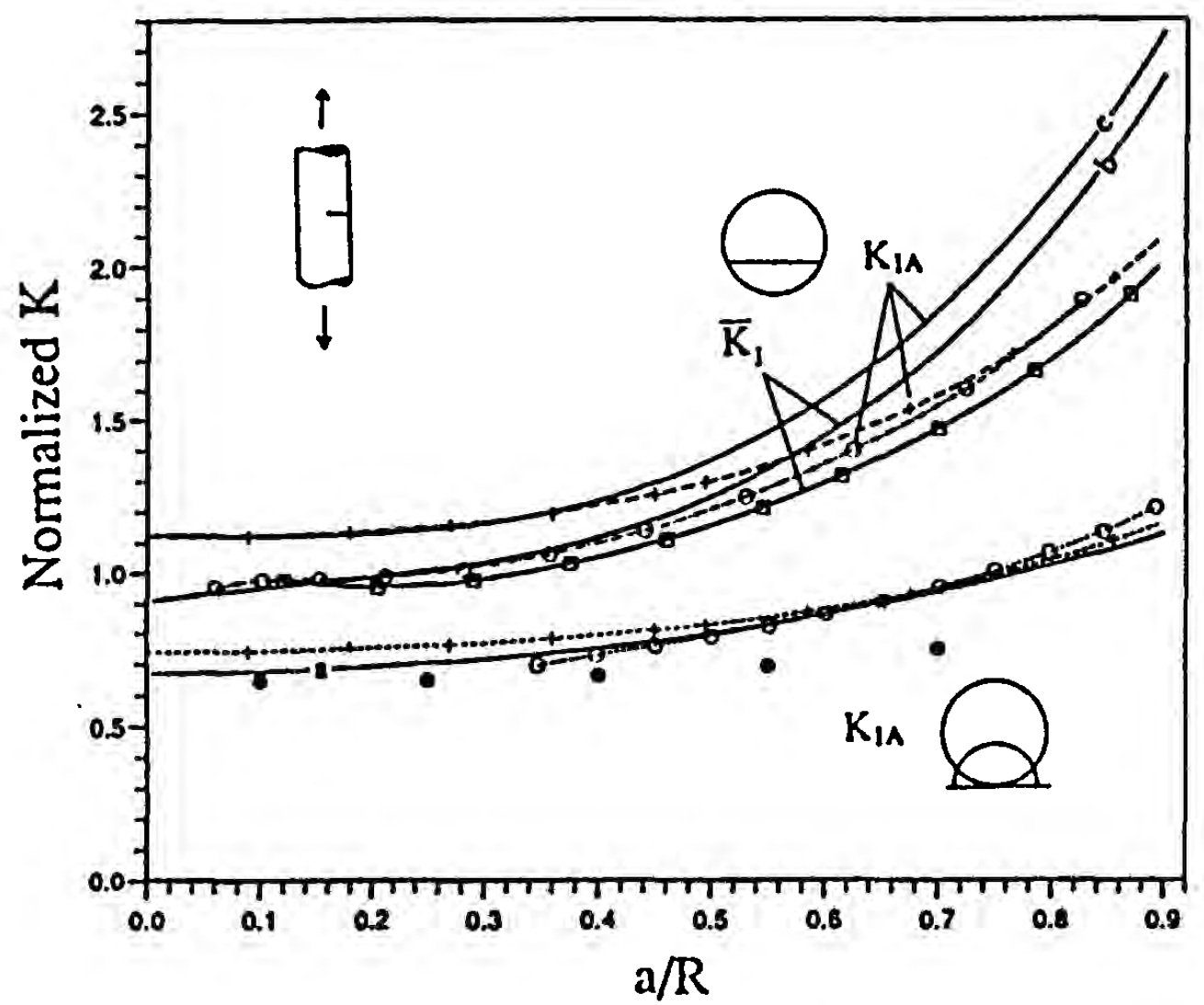

Fig. 20. Comparison with other numerical results for $K_{\mathrm{I}}$ in tension: $\square$ : Daoud et al. [7]. $\bullet$ : Raju et al. [16]. $-+-+:$ Astiz [18]. - $\ominus-$ : Caspers et al. [19]. —— : Present results (a) $K_{\mathrm{I}}$ at the deepest point for semi-circular cracks. (b) Average $K_{\mathrm{I}}$ for straight-fronted cracks. (c) $K_{\mathrm{I}}$ at the deepest point for straight-fronted cracks.

polynomial function of the crack depth $a / D$ and the aspect ratio $a / b$

$$
\frac{K_{\mathrm{IA}}}{\sigma \sqrt{\pi a}}=\sum_{i=0, i \neq 1}^{4} \sum_{j=0}^{3} C_{i j}\left(\frac{a}{D}\right)^{i}\left(\frac{a}{b}\right)^{j}
$$

The configurations which are comparable with those considered in this paper correspond to $a / b=1$ (semi-circular cracks) and $a / b=0$ (straight-fronted cracks).

Investigating part-circular cracks, Caspers et al. [19] also gives normalized $K_{\mathrm{I}}$ at the deepest point in the polynomial form

$$
\frac{K_{\mathrm{IA}}}{\sigma \sqrt{\pi a}}=\sum_{i=0}^{4} \sum_{j=1}^{5} C_{i j}^{(t)}\left(\frac{a_{z}}{R}\right)^{i}\left(\frac{\theta}{\pi}\right)^{j},
$$

where $a_{z}=a-R(1-\cos \theta), \theta$ is the angle at the centre sustended by the arc $B B^{\prime}$ (Fig. 1).

Raju et al. [16] considered nearly semi-elliptical cracks such that the crack front intersected the lateral surface of the bar at $90^{\circ}$ angles. It should be noticed that the so-called crack length in

Table 5. Normalized stress intensity factor at the deepest point [16]

\begin{tabular}{lllllll}
\hline$a / D$ & & 0.050 & 0.125 & 0.200 & 0.275 & 0.350 \\
\hline$\pi / 2 \times K_{\mathrm{IA}} / \sigma \sqrt{\pi a}$ & tensile load & 1.012 & 1.015 & 1.038 & 1.087 & 1.175 \\
& bending load & 0.938 & 0.836 & 0.749 & 0.683 & 0.629 \\
\hline
\end{tabular}


this reference is defined as the arc length measured along the cylindrical surface and not as the major axis of the (nearly) elliptic crack. Thus the results of this reference for $a / c=1$ must be compared to others keeping in mind the difference between the analyzed geometries. The normalized stress intensity factor at point $\mathrm{A}$ for $a / c=1$ are listed in Table 5 .

\section{- Straight-fronted cracks}

Daoud et al. [7] computed $K_{\mathrm{I}}$ assumed to be constant along the crack front

$$
\frac{\bar{K}_{\mathrm{I}}}{\sigma \sqrt{\pi a}}=1.11-3.59 \frac{a}{D}+24.87\left(\frac{a}{D}\right)^{2}-53.39\left(\frac{a}{D}\right)^{3}+57.23\left(\frac{a}{D}\right)^{4}, \quad 0.06 \leqslant a / D \leqslant 0.7
$$

\subsection{Bar under bending}

Figure 21 shows all the numerical results for the case of a bending load. The normalized $K_{\mathrm{I}}$ at point A for $a / c=1$ from Raju et al.'s work [16] is given in Table 5 .

Considering a lateral bending load, Caspers et al. [19] express $K_{1}$ at the deepest point in the same polynomial form as for tension load

$$
\frac{K_{\mathrm{IA}}}{\sigma_{m} \sqrt{\pi a}}=\sum_{i=0}^{4} \sum_{j=1}^{5} C_{i j}^{(b)}\left(\frac{a_{z}}{R}\right)^{i}\left(\frac{\theta}{\pi}\right)^{j} .
$$

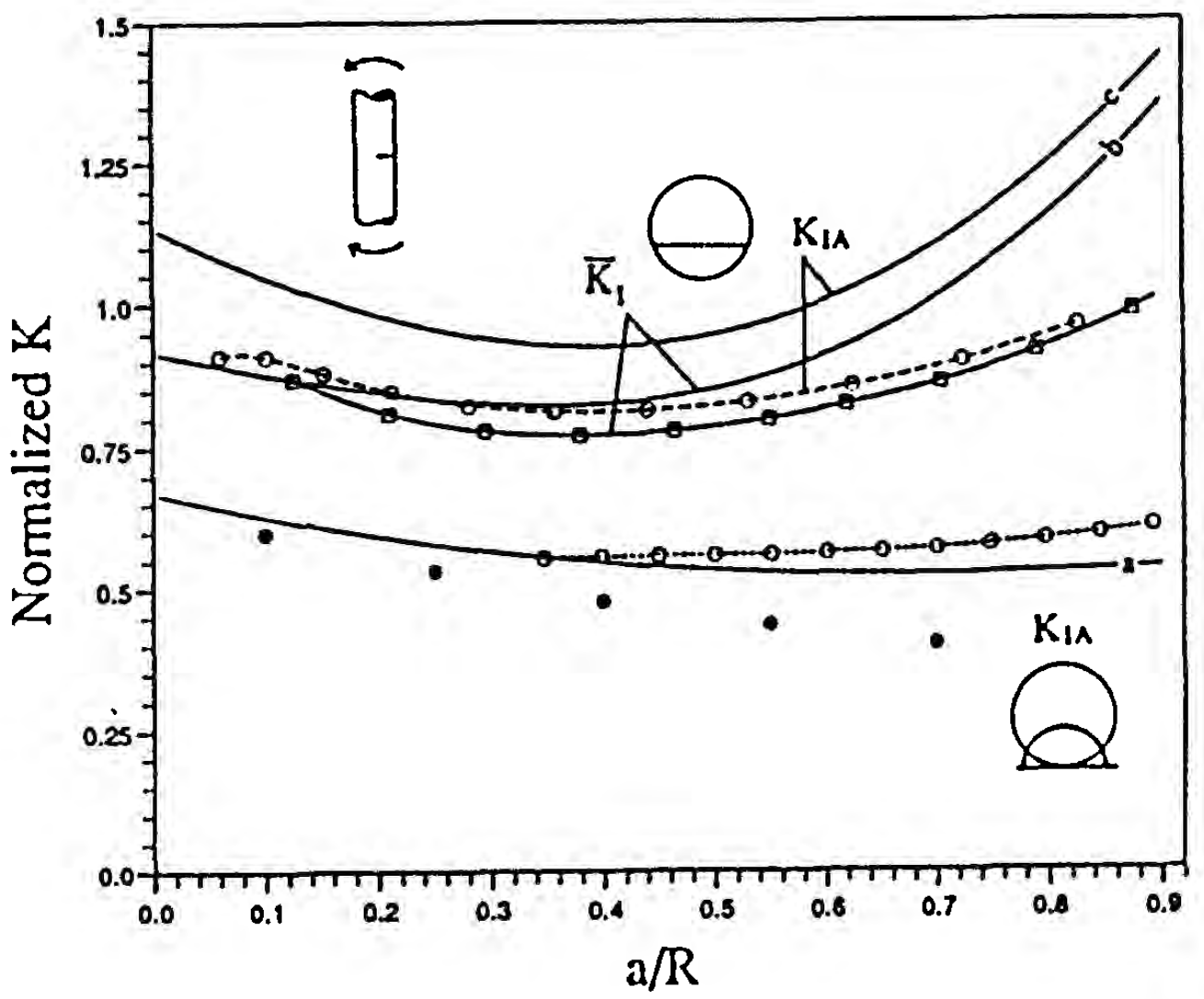

Fig. 21. Comparison with other numerical results for $K_{\mathrm{I}}$ in bending: 
Table 6. Normalized $K_{\mathrm{I}}$ at the deepest point for a semi-circular crack in the half-space under tensile load. In parentheses: value given in the bending case.

Percent difference $=($ present result $/$ referenced result -1$) \times 100$

\begin{tabular}{llllccc}
\hline Reference & $\begin{array}{l}\text { Smith et al. } \\
(1967)[33]\end{array}$ & $\begin{array}{l}\text { Newman } \\
(1973)[34]\end{array}$ & $\begin{array}{l}\text { Nisitani et al. } \\
(1974)[35]\end{array}$ & $\begin{array}{l}\text { Newman et al. } \\
(1981)[36]\end{array}$ & $\begin{array}{l}\text { Isida et al. } \\
(1984)[37]\end{array}$ & $\begin{array}{l}\text { Present } \\
\text { result }\end{array}$ \\
\hline$K_{\mathrm{IA}} / \sigma \sqrt{(\pi a)}$ & 0.656 & 0.656 & 0.636 & 0.662 & 0.659 & 0.668 \\
& & 2 & 5 & $(0.662)$ & $(0.659)$ & $(0.670)$ \\
$\begin{array}{l}\text { Difference } \\
\text { (percent) }\end{array}$ & 2 & & 1.4 & & \\
\hline
\end{tabular}

It should be mentioned that in [19] the linearly distributed stress is zero at the deepest point level $\left(x_{1}=-R+a\right.$, Fig. 1$)$ and not at the diameter level $\left(x_{1}=0\right)$. An adequate combination of (32) and (34) must be carried out to obtain the results for the bending case.

- Straight-fronted cracks

Daoud et al. [14] computed the average $\bar{K}_{1}$ over the crack front

$$
\begin{aligned}
\frac{\bar{K}_{\mathrm{I}}}{\sigma_{m} \sqrt{\pi a}}= & 1.04-3.64 \frac{a}{D}+16.86\left(\frac{a}{D}\right)^{2}-32.59\left(\frac{a}{D}\right)^{3}+28.41\left(\frac{a}{D}\right)^{4}, \\
& 0.0625 \leqslant a / D \leqslant 0.625 .
\end{aligned}
$$

- Figures 20 and 21 show a good agreement between different numerical results concerning semi-circular cracks, both in tension and bending cases. As regards straight-fronted cracks, the results agree well only for small crack depths. It should be mentioned that $K_{\mathrm{IA}}$ values for straight-fronted cracks given in [19] are rather low and thus are closer to $\overline{\boldsymbol{K}}_{\mathrm{I}}$.

- Limiting configuration of very small semi-circular cracks

Let us now consider the limiting case when the radius of the semi-circular crack $R^{\prime}=a$ tends to zero. The limit value of $K_{1}$ at the deepest point $\mathrm{A}$ is found to be 0.668 and 0.670 , respectively, for the tensile and bending load. On the other hand, since this value must be the same as for a semi-circular crack in the half-space, it can be compared to the limit values obtained by earlier investigators treating the half-space problem. Table 6 shows that the differences are really small, except for Nisitani et al.'s value which amounts to 5 percent above the present result.

\section{Conclusion}

The obtained results have brought additional information to the problem of the elastic cracked bar, especially in mode I. A methodical use of integral equations has proved efficient in that it allows the following possibilities:

- the computation of stress intensity factors at any point of the crack front (except for the surface terminating points),

- the simultaneous study of modes I, II and III, 
- the polynomial fitting of numerical values providing the stress intensity factors as functions of three geometrical parameters: the crack depth $a$, the crack radius $R^{\prime}$ and the abscissa $s$ measured on the crack front,

- the results applicable to three basic loads: tension, bending and torsion.

Limiting values of stress intensity factors when the crack depth tends to zero have been found to be in full agreement with the theoretical values for the half-space problem. Furthermore, the numerical values have been compared with both experimental and numerical results available in the literature, which are mainly concerned with the opening mode. A good agreement between the different results has been observed for small crack depths. Nevertheless, for large crack depths for factor $K_{\mathrm{I}}$ increases more rapidly than others. The discrepancy is the more important for straight-fronted cracks.

Since no comparison is possible in modes II and III, it is assumed that the computation which is validated in mode I, also gives acceptable results for other modes. In fact, tests conducted on problems having known analytical solutions have shown that the numerical accuracy is higher in mode I problems than in others.

The polynomial fitting of the results has allowed a rapid and accurate calculation of the stress intensity factors as a function of the crack configuration and the applied loads. Also, the knowledge of these factors all along the crack front has made it possible to investigate either elastic fracture criteria or the fatigue crack growth behaviour. As an application of the results, the crack shapes verifying the iso- $K_{1}$ criterion have been computed in mode I fatigue problems.

Of course, the obtained results are not influenced by the Young modulus value but they do depend on Poisson's ratio $v$ as shown by the governing equations (1) and (2). The computation has been carried out with $v$ equal to 0.3 .

The effect of Poisson's ratio upon the crack shape can be investigated as an extension of the present work. Besides, the proposed integral equation formulation can be applied without major modifications to the problem of thick-walled cylinders containing through- or part-through cracks.

\section{References}

1. A. Athanassiadis, J.M. Boissenot, P. Brevet, D. François and A. Raharinaivo, International Journal of Fracture 17,6 (1981) 553--566.

2. A.S. Salah el din and J.M. Lovegrove, International Journal of Fatigue 3 (1981) 117-123.

3. K. Nezu, S. Machida and H. Nakamura, in The 25th Iapan Congress on Material Research, Metallic Metals (1982) $87-92$.

4. D. Wilhem, J. FitzGerald, J. Carter and D. Dittmer, in Advances in Fracture Research-Fracture 81 . Proceedings of the 5th International Conference on Fracture Research (ICF-5), D. François (ed.), Pergamon Press (1982) 11-21.

5. R.G. Forman and V. Skivakumar, in Fracture Mechanics, vol. 17, ASTM STP 905, 17th National Symposium on Fracture Mechanics, Albany, New York (1986) 59-74.

6. A.J. Bush, in Proceedings of the Society for Experimental Stress Analysis 33, 2 (1976) $249-257$.

7. O.E.K. Daoud, D.J. Cartwright and M. Carney, Journal of Strain Analysis 13, 2 (1978) 83-89.

8. M. Astiz, M. Elices, J. Morton and A. Valiente, in Proceedings of the Society for Experimental Stress Analysis, Spring Meeting, Dearborn, Michigan (1981) 277-282.

9. A.J. Bush, Journal of Testing and Eraluation 9, 4. July (1981) 216-233.

10. M.A. Astiz, M. Elices and A. Valiente. European Congress on Fracture $(E C F-6)(1986) 65-74$.

11. W.S. Blackburn, Engineering Fracture Mechanic's 8 (1976) $731 \ldots 736$.

12. M.A. Astiz and M. Elices, in Proceedings of the Second International Conference on Numerical Methods in Fracture Mechanic's. Pineridge Press, Swansea (1980) 93106. 
13. Y-X. Fan, Y-T. Fan and D-J. Fan, Engineering Fracture Mechanics 16, 1 (1982) 55-67.

14. O.E.K. Daoud and D.J. Cartwright, Engineering Fracture Mechanics 19, 4 (1984) 701-707.

15. O.E.K. Daoud and D.J. Cartwright, Journal of Strain Analysis 20, 1 (1985) 53-58.

16. I.S. Raju and J.C. Newman, in Fracture Mechanics, vol. 17, ASTM STP 905, 17th National Symposium on Fracture Mechanics, Albany, New York (1986) 789-805.

17. K.J. Nord and T.J. Chung, International Journal of Fracture 30 (1986) 47-55.

18. M.A. Astiz, International Journal of Fracture 31 (1986) 105-124.

19. M. Caspers and C. Mattheck, Fatigue and Fracture of Enyineering Materials Structures 9, 5 (1987) 329-341.

20. J.H. Underwood and R.L. Woodward, Experimental Mechanics 29, 2 (1989) 66-168.

21. E. Si, Engineering Fracture Mechanics 37, 4 (1990) 805-812.

22. A. Levan and J. Royer, International Journal of Fracture 31 (1986) 125-142.

23. H.D. Bui, Journal of Mechanics and Physics of Solids 25 (1977) 29-39.

24. V.D. Kupradze, T.G. Gegelia, M.O. Bashelishvili and T.V. Burchuladze, Three-dimensional Problems of the Mathematical Theory of Elasticity and Thermoelasticity, North Holland (1979).

25. R.S. Barsoum, International Journal of Numerical Methods in Engineering 10, 1 (1976) 25-37.

26. A. Levan and B. Peseux, International Journal for Numerical Methods in Engineering 26 (1988) 2383-2402.

27. W.G. Knauss, International Journal of Fracture 6, 2 (1970) 183-187.

28. E. Sommer, Engineering Fracture Mechanics 1, 3 (1969) 539-546.

29. Z.P. Bazant and L.F. Estenssoro, International Journal of Solids and Structures 15 (1979) 405-426.

30. W.T. Koiter, Journal of Applied Mechanics 23 (1965) 237.

31. H. Tada, P. Paris and G. Irwin, The Stress Analysis of Cracks Handbook, Del Research Corporation (1973).

32. R.G. Forman, V. Shivakumar, J.C. Newman, L. Williams and S. Piotrowski, Fatigue crack growth computer program, NASA/FLAGRO, Version June (1985).

33. F.W. Smith, A.S. Kobayashi and A.F. Emery, Journal of Applied Mechanics, December (1967) 953-959.

34. J.C. Newman, Engineering Fracture Mechanics 5 (1973) 667-689.

35. H. Nisitani and Y. Murakami, International Journal of Fracture 10, 3 (1974) 353-368.

36. J.C. Newman and I.S. Raju, Enyineering Fracture Mechanics 15, 1-2 (1981) 185-192.

37. M. Isida, H. Noguchi and T. Yoshida, International Journal of Fracture 2 (1984) 157-188. 